NBER WORKING PAPER SERIES

\title{
OPTIMAL RECURSIVE REFINANCING AND \\ THE VALUATION OF MORTGAGE-BACKED SECURITIES
}

\author{
Francis A. Longstaff \\ Working Paper 10422 \\ http://www.nber.org/papers/w10422 \\ NATIONAL BUREAU OF ECONOMIC RESEARCH \\ 1050 Massachusetts Avenue \\ Cambridge, MA 02138 \\ April 2004
}

I am grateful for helpful discussions with David Armstrong, Douglas Breeden, Stephen Cauley, Robert Edelstein, Jim Gammill, Kent Hatch, Lakhbir Hayre, Dwight Jaffe, Hedi Kallal, Stanley Kon, Eduardo Schwartz, Tony Sanders, Roberto Sella, Chester Spatt, Richard Stanton, and Nancy Wallace and for the comments of seminar participants at the University of California at Berkeley, Brigham Young University, Citigroup, Cornell University, Morgan Stanley, New York University, Stanford University, The Wharton School at the University of Pennsylvania, and Yale University. I am also grateful to Brett Myers for research assistance. All errors are my responsibility. The views expressed herein are those of the author(s) and not necessarily those of the National Bureau of Economic Research.

(C2004 by Francis A. Longstaff. All rights reserved. Short sections of text, not to exceed two paragraphs, may be quoted without explicit permission provided that full credit, including (C) notice, is given to the source. 
Optimal Recursive Refinancing and the Valuation of Mortgage-Backed Securities

Francis A. Longstaff

NBER Working Paper No. 10422

April 2004

JEL No. G1

\section{$\underline{\text { ABSTRACT }}$}

We study the optimal recursive refinancing problem where a borrower minimizes his lifetime mortgage costs by repeatedly refinancing when rates drop sufficiently. Key factors affecting the optimal decision are the cost of refinancing and the possibility that the mortgagor may have to refinance at a premium rate because of his credit. The optimal recursive strategy often results in prepayment being delayed significantly relative to traditional models. Furthermore, mortgage values can exceed par by much more than the cost of refinancing. Applying the recursive model to an extensive sample of mortgage-backed security prices, we find that the implied credit spreads that match these prices closely parallel borrowers' actual spreads at the origination of the mortgage. These results suggest that optimal recursive models may provide a promising alternative to the reduced-form prepayment models widely used in practice.

Francis A. Longstaff

UCLA

Anderson Graduate School of Management

110 Westwood Plaza, Box 951481

Los Angeles, CA 90095-1481

and NBER

francis.longstaff@anderson.ucla.edu 


\section{INTRODUCTION}

Since its inception in the 1970s, the mortgage-backed security market has experienced dramatic growth in the United States. As of June 30, 2002, the total notional amount of Agency mortgage-backed securities and collateralized mortgage obligations outstanding was more than $\$ 3.9$ trillion. This means that the size of these markets now exceeds the $\$ 3.5$ trillion notional amount of publicly-traded U.S. Treasury debt.

Despite the importance of these markets, however, the goal of developing a fundamental theory of mortgage valuation represents an ongoing challenge to researchers. The key element that has proven difficult to explain within a rational model is how mortgage borrowers choose to refinance their loans. Influential early work by Dunn and McConnell (1981a, b), Brennan and Schwartz (1985), and others applies contingent claims techniques to the problem by modeling prepayment as an endogenous decision made by the borrower in minimizing the present value of his current mortgage. More recently, Dunn and Spatt (1986) and Stanton and Wallace (1998) extend this classical approach in an important way by modeling the prepayment decision as the result of the borrower minimizing his lifetime mortgage costs. As discussed by Schwartz and Torous $(1989,1992,1993)$, however, actual prepayment behavior appears very suboptimal relative to the optimal behavior implied by these models. Furthermore, these models all have the property that mortgage-backed security prices cannot exceed par plus the number of points paid to refinance the loan. As demonstrated by Stanton (1995), Boudoukh, Whitelaw, Richardson, and Stanton (1997), and others, this upper bound is nearly always violated in practice.

The apparent failure of the optimal prepayment literature led to the current generation of reduced-form or behavioral mortgage valuation models. In this approach, econometric models of prepayment behavior are estimated from historical data and are then used to forecast future prepayments. Important examples of this widelyused modeling approach include Schwartz and Torous (1989, 1992, 1993), Boudoukh, Whitelaw, Richardson, and Stanton (1997), Hayre (2001), and many others. An important drawback of these descriptive models, however, is that they may do very poorly out of sample when the current or expected shape of the term structure differs from those experienced during the historical calibration period. Thus, this approach can impose significant model risk on market participants during periods when the characteristics of the market differ from their historical patterns.

The drawbacks of reduced-form models provide a strong motivation for revisiting the optimal prepayment modeling approach. Interestingly, a common feature throughout the earlier literature is the assumption that the rate at which a borrower can refinance his loan is independent of his financial status. In actuality, however, a 
borrower who does not satisfy the strictest underwriting guidelines may have to refinance at a higher rate than other more-qualified borrowers. This clearly would reduce his incentives for prepaying his current mortgage and affect his optimal refinancing strategy. Thus, even though principal and interest on an Agency mortgage-backed security are guaranteed, the actual timing of these cash flows could be affected by the credit of the borrower, which in turn would be reflected in the value of the security.

In this paper, we solve for the optimal recursive refinancing strategy of a borrower whose objective is to minimize his lifetime mortgage costs, and then examine the implications of this strategy for the valuation of mortgage-backed securities. Our approach incorporates the effects of the following key factors on the optimal refinancing strategy:

- The transaction costs associated with refinancing a mortgage.

- The probability of prepaying for exogenous reasons.

- The credit spread faced by a borrower who is considering refinancing.

Since the nature of the recursive problem requires considering the effects of decisions going far beyond the current mortgage, it is important to use a modeling framework that reflects the actual intertemporal behavior of the term structure. In light of this, we develop the model within a realistic multi-factor term-structure setting that matches both the current term structure and the values of fixed income options. The use of a multi-factor model is also consistent with Boudoukh, Whitelaw, Richardson, and Stanton (1997) and Downing, Stanton, and Wallace (2002) who find evidence that mortgage-backed security prices are driven by multiple term-structure factors. Since the recursive refinancing problem is essentially an American option valuation problem, we use the least-squares simulation method of Longstaff and Schwartz (2001) to solve for the optimal recursive strategy and value mortgage-backed securities in this multifactor framework.

We show that the optimal recursive strategy implies prepayment behavior very different from that given by classical rational prepayment models. For example, the mean time to prepayment of the current mortgage can be several years later under the optimal recursive strategy when the borrower is not able to refinance at the par mortgage rate. Furthermore, a borrower attempting to minimize lifetime mortgage costs has a strong incentive to minimize the number of times he refinances his mortgage because of the associated transaction costs. Thus, a borrower who believes that mortgage rates may be going down further in the near future may choose to delay refinancing his loan. This is particularly true when there is a significant possibility that the borrower may need to pay off the loan for exogenous reasons in the near future anyway. Because the first prepayment may occur much later when the optimal recursive strategy is followed, the value of a mortgage-backed security can be significantly higher than par plus the costs of refinancing. 
To explore the valuation implications of the model, we collect monthly prices for mortgage-backed securities with coupon rates ranging from 5.50 to 9.50 percent for the 1992-2002 period. Calibrating the model to the swap curve and the prices of interest rate caps and swaptions for the corresponding months, we solve for the implied mortgage turnover rate and credit spreads that match the historical data. The mean mortgage turnover rate implied from the data is 5.59 percent, which closely approximates the actual historical turnover rate of 6.04 percent. Similarly, the implied credit spreads needed to match the cross section of mortgage-backed security prices in the sample range from zero to about 150 basis points. These implied credit spreads closely parallel actual credit spreads observed in the market at the time the mortgages are originated and are also consistent with mortgage spreads in the rapidly-growing subprime mortgage market. These results strongly suggest that mortgage-backed security prices can be reconciled within a rational model by taking into account the credit of the borrower. We also examine the out-of-sample pricing performance of the model by calibrating it using ex ante data and then comparing implied model prices to actual market mortgage-backed security prices. We find that the model is able to capture more than 97 percent of the variation in the data over the past decade and provides unbiased estimates of overall mortgage-backed security prices. Thus, optimal recursive models may provide a viable alternative to the reduced-form or behavioral prepayment models widely used in practice.

The remainder of this paper is organized as follows. Section 2 describes the mortgage-backed security market. Section 3 discusses the literature. Section 4 presents the optimal recursive refinancing model. Section 5 provides numerical examples. Section 6 describes the data used in the study. Section 7 provides a preliminary regression analysis of the properties of mortgage-backed security prices. Section 8 examines the implications of the model for mortgage-backed security valuation. Section 9 examines the out-of-sample performance of the recursive model in valuing mortgage-backed securities. Section 10 summarizes the results and makes concluding remarks.

\section{MORTGAGE-BACKED SECURITIES}

A mortgage-backed security is a claim to the cash flows generated by a specific pool of mortgages. Most mortgage-backed securities are issued by one of three Government Sponsored Enterprises or Agencies known as Ginnie Mae (GNMA), Freddie Mac (FHLMC), and Fannie Mae (FNMA), although there is a growing trend toward mortgage-backed securities being issued directly by large mortgage lenders. Since their inception in the 1970s, mortgage-backed securities have become very popular as an investment vehicle among individual and institutional fixed income investors. Key reasons for this popularity are that mortgage-backed securities offer attractive yields, have little or no credit risk, and trade in a liquid secondary market. 
To illustrate the mechanics of how mortgage-backed securities work, let us consider the Ginnie Mae I mortgage-backed security program as an specific example. Under this program, the creation of a mortgage-backed security begins with a Ginnie Mae approved mortgage lender or issuer originating a pool of FHA insured or VA guaranteed mortgage loans secured by single-family homes. To be eligible for the Ginnie Mae I program, these mortgage loans must have the same mortgage rate and meet specific documentation and origination guidelines. As an example, assume that the pool of mortgages consists of recently originated 30-year loans with a fixed coupon rate of 7.00 percent. Securitized by these loans, the issuer then structures a mortgagebacked security with a coupon rate equal to 6.50 percent and a total notional amount equal to the aggregate principal amount of the underlying mortgage pool ( $\$ 1$ million minimum pool size). The issuer then sells the mortgage-backed security to investors either directly or through a network of Wall Street dealers.

The coupon rate on the mortgage-backed security is lower than the mortgage rate since the issuer receives a 50 basis point fee for servicing the mortgages and passing through interest payments and scheduled and unscheduled principal to investors. In the case of delinquent loans, the mortgage-backed security issuer has the responsibility to advance funds from his own account to make the scheduled payments. Out of the 50 basis point fee received by the issuer, however, the issuer must also pay Ginnie Mae a six basis point guarantee fee. For this fee, Ginnie Mae guarantees the timely payment of principal and interest on the mortgage-backed security to the investors. Thus, because of the Ginnie Mae guarantee, investors do not face the risk of losses arising from delinquent payments or from foreclosures or bankruptcies among the mortgages in the underlying mortgage pool. The Ginnie Mae guarantee is backed by the full faith and credit of the United States. Mortgage-backed securities issued by Freddie Mac or Fannie Mae are guaranteed by the respective agencies and bear credit risk similar to their debt, which is rated AAA (or better). GNMA I mortgage-backed securities generally exist only in book-entry form and are issued in minimum denominations of $\$ 25,000$.

To simplify the pass through of interest and principal from borrowers to the mortgage-backed security investors, monthly payments are made on a prespecified schedule. In particular, the interest and principal collected by the mortgage servicer during a month is paid out to the investors 15 days after the end of the month in which the interest accrues. For other mortgage-backed security programs, the delay can be between 15 to 45 days. Because of this, there can be a slight timing mismatch between the cash flows on the underlying pool of mortgages and those on the mortgage-backed security.

If borrowers did not have the option to prepay their loans, the value of a mortgagebacked security would simply be the value of a fixed 30-year annuity. Because of the prepayment option, however, principal is returned at varying times. Mortgagebacked security valuation is complicated because the timing of these prepayments 
may be determined by both random and strategic factors. For example, a borrower may prepay his mortgage for exogenous reasons such as moving even though market rates may be higher than his current mortgage rate. Alternatively, a borrower may strategically decide to refinance his mortgage when market rates are below his current mortgage rate.

It is important to observe, however, that the decision to refinance a mortgage does not depend solely on the relation between the borrower's current mortgage rate and the prevailing market rate. To prepay his existing mortgage and refinance the loan, the borrower needs to qualify for a new mortgage loan. To do this, the borrower needs to meet a number of income, credit, documentation, employment, loan-to-value, and debt-to-income standards. If the borrower's personal financial situation is such that he is marginal in meeting some of these criteria, he may have fewer choices of lenders available to him and may only be able to refinance at a premium rate (if at all). To illustrate how the borrower's financial situation may affect the rate at which he can refinance, note that a VA borrower who refinances his mortgage but puts down less than five percent of the value of his home must pay a three point VA funding fee in addition to the usual origination costs paid to a mortgage lender. By making a larger down payment, however, the VA borrower may be able to reduce this fee to 1.25 points. A similar sliding schedule of mortgage insurance fees applies to standard FHA mortgages. Thus, a mortgage borrower who is cash constrained or whose home has declined in value relative to the mortgage balance faces significantly higher costs to refinance. Since these costs are typically absorbed into the refinanced mortgage, they serve to increase the effective rate at which the borrower is able to refinance. The GNMA I program allows premium mortgages with rates as high as 150 basis points above the prevailing GNMA mortgage rate to be pooled into a mortgage-backed security.

Furthermore, a FHA or VA borrower who has recently gone through bankruptcy, a period of unemployment, or other credit problems, or who has a judgment against him, is unable or unwilling to document his income, or in other ways fails to meet standard underwriting requirements, may not be able to refinance into a new FHA or VA loan. In some cases, these nonconforming borrowers may be able to find conventional lenders with less stringent criteria who would be willing to refinance the loan, albeit at a premium rate. If the borrower's credit is sufficiently bad that he cannot refinance with a conventional lender at all, he may then need to go to the subprime mortgage market. This is a rapidly growing sector of the mortgage market that specializes in making loans to borrowers with impaired credit. A quick search of the web reveals a vast array of subprime mortgage products available to borrowers (often with names such as "bad credit mortgage loans"). Laderman (2001) reports that subprime mortgage originations as a share of total mortgage originations grew from five percent in 1994 to 13.4 percent in 2000. Laderman also shows that subprime mortgage rates averaged roughly 370 basis points higher than prime mortgage rates during the 1994 to 2000 period, and were about 300 basis points at the end of 2001. These considerations 
make clear that the financial situation of a borrower can affect the rate at which he can refinance. This makes a strong case for incorporating credit into the analysis of mortgage-backed securities. Clearly, to be successful, a mortgage valuation framework needs to capture the economics of how borrowers choose to exercise their prepayment option and refinance their mortgage. To provide historical perspective to the problem, some of the ways in which mortgage prepayments have been modeled are described in the next section.

\section{THE LITERATURE}

In important early work, Dunn and McConnell (1981a, b) were the first to apply a contingent-claims approach to valuing mortgage-backed securities. In their approach, a mortgage-backed security is modeled as a combination of a long position in an annuity and a short American call option on that annuity. Using a single-factor Cox, Ingersoll, and Ross (1985) model to describe interest rate dynamics, the short call option is priced by solving for the prepayment rule that maximizes its value using standard American option valuation techniques. This is equivalent to minimizing the value of the mortgage-backed security that the investor holds, or alternatively, minimizing the value of the current mortgage. To capture the feature that borrowers may prepay mortgages for exogenous reasons, Dunn and McConnell also allow prepayment to be triggered by the realization of a Poisson event. Numerical values for GNMA mortgagebacked securities are obtained by solving the associated partial differential equation using finite difference techniques. A similar approach is taken in Brennan and Schwartz (1985) who use a two-factor term structure model. Other related papers that adopt a similar approach but with transaction costs include Timmis (1985), Dunn and Spatt (1986), Johnston and Van Drunen (1988), and McConnell and Singh (1994). In an important extension to this contingent claims framework, Dunn and Spatt (1986) model the prepayment decision as the result of a borrower attempting to minimize his lifetime mortgage costs. Stanton and Wallace (1998) present a numerical algorithm for solving the resulting recursive prepayment problem and generalize the framework to include the possibility of prepayments for exogenous reasons.

As discussed by Stanton (1995), however, a major drawback of these early rational prepayment models is that they imply upper bounds on the values of mortgage-backed securities that are often violated in practice. In Dunn and McConnell (1981a, b), for example, the maximum value that a mortgage-backed security can attain is 100. Similarly, in Dunn and Spatt (1986), mortgage-backed security prices are bounded above by 100 plus the number of points paid by the borrower to refinance his loan. In actuality, high-coupon mortgage-backed securities with prices in the range of 105 to 110 are common. Since transactions costs of five to ten percent are implausible, the upper bounds implied by these models are clearly inconsistent with market prices. Equivalently, the prepayment strategies generated by these rational prepayment models 
imply that mortgages typically should be paid off at a rate much faster than actually observed.

Given the inability of these optimal prepayment models to match observed prepayment behavior or to explain premium mortgage-backed security prices, it is perhaps not surprising that the next generation of models focused on incorporating empirical descriptions of prepayment behavior into the valuation framework. Important examples of this approach include Schwartz and Torous (1989, 1992, 1993). In these papers, rather than imposing an optimal value-minimizing call condition, Schwartz and Torous use historical prepayment data to estimate a hazard rate function for the probability that a borrower will prepay his mortgage. The estimated empirical prepayment function is used to generate mortgage cash flows over time and along the simulated paths generated by a one- or two-factor model of the term structure. The simulated mortgage cash flows are then easily valued by discounting them back along the interest rate paths and then averaging across paths. This empirical or reduced-form approach quickly became the standard way on Wall Street of modeling prepayment behavior and valuing mortgage-backed securities. There are numerous in-depth descriptions of the implementation of this approach. As an example, see Hayre and Young (2001).

While reduced-form models have the advantage of fitting historical prepayment behavior, they have a number of important drawbacks. For example, Stanton (1995) observes that since these models are only descriptive of historical prepayment behavior, it is not clear how they would perform in a different economic environment. In particular, if the current or expected shape of the term structure were to differ from those experienced historically, then the prepayment model might do very poorly out of sample. Reduced-form models are heavily dependent on the assumption that future prepayment behavior is predictable on the basis of historical prepayment behavior. Because of this feature, they impose significant model risk on market participants who rely on them.

In an interesting recent paper, Stanton (1995) presents a framework for valuing mortgage-backed securities in which elements of both rational and exogenously determined prepayment strategies are included. Specifically, borrowers attempt to minimize the value of their current mortgage by making optimal prepayment decisions given their transaction costs. The borrower, however, is only allowed to consider whether prepayment is optimal at random times given by the realization of a Poisson process. Thus, while the model results in prepayments that are delayed relative to those implied by earlier rational prepayment models, this delay is imposed exogenously. In fairness to the model, however, Stanton's primary focus is on demonstrating how heterogeneity in transaction costs can reproduce a number of stylized facts about mortgage-backed securities such as the burnout factor in prepayments. Although we do not consider the effects of heterogeneity in this paper, Stanton's results would clearly generalize to our modeling framework as well. 
Finally, we note a number of other papers which also address the valuation of mortgage-backed securities. Recently, Boudoukh, Whitelaw, Richardson, and Stanton (1997) use a nonparametric multivariate density approach to approximate the functional dependence of mortgage-backed security prices on term structure factors. Their paper documents the important result that mortgage-backed security prices are influenced by at least two distinct interest rate factors. A similar result is also documented by Downing, Stanton, and Wallace (2002). Dunn and Singleton (1983) find evidence that the relative pricing of GNMA mortgage-backed securities and Treasury bonds is consistent with a consumption-based asset pricing model. Dunn and Spatt (1985, 1988), Chari and Jagannathan (1989), Leroy (1996), and Stanton and Wallace (1998) consider the effects of borrower mobility or choice on mortgage markets. Finally, Dunn and Spatt (1999) study the effects of callability, points, and contract length on the pricing of debt contracts.

\section{THE RECURSIVE REFINANCING MODEL}

In this section, we present the optimal recursive refinancing model. In doing this, we first describe the multi-factor term structure framework used to model the dynamics of interest rates. We then explain how the optimal recursive strategy can be determined by an application of the least-squares simulation methodology (LSM) used by Longstaff and Schwartz (2001), Longstaff, Santa-Clara, and Schwartz (2001a), and others in valuing American options.

As described, the early literature on rational prepayment assumes that the borrower attempts to minimize the value of his current mortgage, or equivalently, attempts to maximize the value of the option that the mortgage lender is short. Given this objective function, the prepayment decision becomes intertemporally separable and can be made without considering any of the cash flows associated with future mortgages. When there are refinancing costs, however, the prepayment decision is no longer separable and a utility maximizing borrower needs to take into account the intertemporal effects of prepayment. Most individuals who prepay their mortgage will not be able to pay off the loan in cash, and will need to refinance their mortgage. Thus, both the transaction costs of refinancing as well as the rate at which the borrower can borrow in the future become relevant to making current decisions. For example, because of the costs of refinancing, the borrower has clear incentives to minimize the number of times he refinances during his lifetime. This means that a borrower who is considering refinancing needs to take into account the likelihood that rates might decrease further and that he may want to refinance yet again in the near future.

In this paper, we follow Dunn and Spatt (1986) and Stanton and Wallace (1998) and take the objective function of the borrower to be the minimization of the present value of his lifetime mortgage-related cash flows. These cash flows include interest, principal, and any points and/or transaction costs involved in refinancing the mortgage 
(potentially repeatedly) over time. A key distinguishing feature of our approach is that it explicitly allows for the possibility that the borrower may not be able to refinance at the par mortgage rate because of his financial or credit situation. Our framework also incorporates refinancing costs or points and allows for possibility that the mortgage may be prepaid for exogenous reasons. For simplicity, we assume that the lifetime of the borrower coincides with the 30-year horizon of his initial mortgage. This assumption, however, is not crucial to the problem and could easily be relaxed.

\subsection{The Term Structure Model}

Since making an optimal recursive prepayment decision requires anticipating the characteristics of prepayment decisions far in the future, it is important that the model imply realistic term structure dynamics. To this end, we use a simple version of the string market model framework used in Santa-Clara and Sornette (2001), Longstaff and Schwartz (2001), Longstaff, Santa-Clara, and Schwartz (2001a, b), Han (2002), and others. This framework can also be viewed as equivalent to a Heath, Jarrow, and Morton (1992) or Brace, Gatarek, and Musiela (1997) model in which the covariance structure among forward rates is specified directly.

For notational simplicity, we denote the valuation date as time zero. The underlying string to be simulated is the vector $D$ of discount bonds with maturities ranging from three months to 30 years in increments of three months. ${ }^{1}$ Let $D_{i}$ denote the price of the zero-coupon bond with maturity date $i / 4$, where $i=1,2, \ldots, 120$. Since the expected return of each discount bond is just the the short-term rate $r$ under the risk-neutral measure, we only need to specify the volatility and correlation structure of $D$ to complete the specification of the term structure dynamics.

In doing this, we follow Heath, Jarrow, and Morton (1992), Brace, Gatarek, and Musiela (1997), Longstaff, Santa-Clara, and Schwartz (2001a, b), and many others by first specifying the volatility and correlation structure among forward rates. From this, the volatility and correlation structure of $D$ are easily obtained by a change of variables. Let $F_{i}$ represent the forward three-month rate given by $4\left(D_{i} / D_{i+1}-1\right)$. We assume that the risk-neutral dynamics for each forward rate are given by

$$
d F_{i}=\mu_{i} d t+\sigma d Z_{i}
$$

where $\mu_{i}$ is an unspecified drift function, $\sigma$ is a deterministic volatility function, and $d Z_{i}$ is a standard Brownian motion specific to this forward rate. Note that although each forward rate has its own $d Z_{i}$ term, these terms are correlated across forwards. To allow a simple time-homogeneous correlation structure, we assume that the $i j$-th

\footnotetext{
${ }^{1}$ We use three-month time increments rather than the customary one-month time increments to reduce the memory and computational requirements of the algorithm. This simplification has little or no effect on any of the results.
} 
element of the correlation matrix $\Sigma$ for the Brownian motions is given by $e^{-\gamma|i-j|}$. When $\gamma>0$, the correlation matrix $\Sigma$ is of full rank. ${ }^{2}$ Thus, this string market model can be viewed as a 120-dimensional multi-factor model of the term structure. The values of $\sigma$ and $\gamma$ will be chosen to match the market prices of fixed income option values.

Following Longstaff, Santa-Clara, and Schwartz (2001a, b), the risk-neutral dynamics of the vector of discount bond prices can now be expressed as

$$
d D=r D d t+J^{-1} \sigma d Z
$$

where $r$ is the spot rate, $\sigma d Z$ is the vector formed by stacking the individual $\sigma d Z_{i}$ terms in Eq. (1), and $J^{-1}$ is the inverse of the Jacobian matrix for the mapping from discount bonds to forward rates. Since each forward rate depends only on two discount bond prices, this Jacobian matrix has a simple banded diagonal form (see Longstaff, Santa-Clara, and Schwartz (2001b)). The dynamics for $D$ in Eq. (2) provide a complete specification of the evolution of the term structure. This string market model is arbitrage free in the sense that it fits the initial term structure exactly and the expected rate of return on all discount bonds equals the spot rate under the risk-neutral pricing measure.

\subsection{The Recursive Model}

Minimizing his lifetime mortgage costs implies that at each decision date, the borrower must compare the present value of continuing with his current mortgage with the present value of refinancing the mortgage. If the present value of refinancing is lower, then the borrower prepays, and vice versa. In either event, the prepayment decision is revisited at the next decision date.

The optimal recursive prepayment strategy is determined numerically by applying the LSM algorithm of Longstaff and Schwartz (2001). In doing this, we first generate $N$ paths of the vector $D$ by simulating the string market model described above out for 30 years. Since the simulation interval is three months, the stochastic differential equation for $D$ is discretized by applying Ito's Lemma to the logarithm of $D$, simulating the Euler approximation to the stochastic differential equation for the logarithm of $D$, and then exponentiating the resulting expression. This approach results in a much more accurate discretization than applying the Euler approximation directly to the stochastic differential equation for $D$. We use the yield on the zero-coupon bond with maturity three months at each date to approximate the value of $r$. This, combined with the assumption that the volatility function $\sigma$ is zero for horizons less than or

${ }^{2}$ Although this specification for the correlation matrix is chosen for its simplicity, it performs as well as a number of more complex specifications in matching the market prices of swaption values. 
equal to three months guarantees that zero-coupon bonds converge to a value of one on their maturity date.

The next step is to solve for the par mortgage rate at each date along each of the $N$ paths. To explain this, we first need to introduce some notation. Let $\alpha$ be the number of points paid to refinance a mortgage. Let $\beta$ represent the spread above the par mortgage rate at which the borrower can refinance his loan. We assume that exogenous prepayments occur by the realization of an independent Poisson process with intensity parameter $\lambda$. Now, let $V(R, D, t)$ denote the value of a mortgage with coupon rate $R$, given the state vector $D$ at time $t$, and given that the borrower can always borrow at the par mortgage rate $(\beta=0)$. Given this function, the value of the par mortgage rate $R^{*}(D, t)$ can be determined by solving the expression $V\left(R^{*}, D, t\right)=100$.

To approximate the functional form of the value function $V(R, D, t)$, we use the following iterative procedure. Let $A(R, D, t)$ denote the present value at time $t$ of all future cash flows to be paid by a borrower who does not refinance at time $t$ and who can borrow at the par rate. Similarly, let $B(R, D, t)$ denote the present value at time $t$ of all future cash flows to be paid by the same borrower assuming that the mortgage is refinanced at time $t$. Note that both $A(R, D, t)$ and $B(R, D, t)$ are based on the assumption that optimal decisions are made at all future times beyond time $t$.

At the maturity date $T$ of the mortgage, the value of the mortgage $V(R, D, T)$ is clearly zero. Similarly, both $A(R, D, T)$ and $B(R, D, T)$ equal zero. Rolling back to time $T-1$, the present value of continuing with the current mortgage is $A(R, D, T-$ $1)=D(1) P$, where $D(1)$ is the value of a one-period zero-coupon bond and $P$ is the payment given rate $R$. Given this functional form, the value of $R^{*}(D, T-1)$ is easily determined. The present value of refinancing is $B(R, D, T-1)=D(1) P^{*}+\alpha L$ where $P^{*}$ is the payment at the refinanced rate $R^{*}$, and $L$ is the mortgage balance given that the current mortgage rate is $R$. With these present value functions, the decision to refinance at time $T-1$ can be made by simply comparing the values of $A(R, D, T-1)$ and $B(R, D, T-1)$ for each path and taking the decision that results in the lowest cost.

Rolling back to time $T-2$, we note that it is now straightforward to determine the future cash flows from a newly-originated mortgage with coupon rate $R$. Specifically, this mortgage would make a payment $P$ at $T-1$, and the borrower would then decide whether to pay off the mortgage by comparing the values of $A(R, D, T-1)$ and $B(R, D, T-1)$. If it is less costly for the borrower to refinance at $T-1$, or alternatively, if the borrower must pay off his mortgage for exogenous reasons, then the mortgage balance is paid to the mortgageholder and there are no further cash flows. If, on the other hand, it is less costly to continue with the mortgage, then the mortgage continues one more period until $T$. The key point here is that all future cash flows on the mortgage are determined given the functions $A, B$, and $R^{*}$ determined for $t>T-2$. 
Although this procedure allows us to identify the ex post cash flows along each path for the mortgage, what we need is the functional form for the ex ante value of the mortgage $V(R, D, T-2)$. To estimate this functional form, we recall that standard no-arbitrage valuation theory implies that $V(R, D, T-2)$ can be expressed as the conditional expectation of discounted future cash. Thus, the problem of estimating the form of $V(R, D, T-2)$ can be reduced to the problem of finding the conditional expectation of discounted future cash flows, given the current state variables $R$ and $D$. Following Longstaff and Schwartz (2001), we regress the discounted ex post cash flows for each path on functions of the ex ante variables $R$ and $D$. The fitted value from this cross-sectional regression then represents an efficient estimator of the conditional expectation function, and hence, of $V(R, D, T-2)$. Given this estimator of $V(R, D, T-$ 2 ), it is again straightforward to determine the par mortgage rate as the solution of $V\left(R^{*}, D, T-2\right)=100$.

Continuing to solve for the other relevant functions at $T-2$, we follow essentially the same procedure to determine the future cash flows that result from a decision not to refinance. Specifically, the borrower would make a payment $P$ at time $T-1$, and would then decide whether to refinance. If the loan was not refinanced at $T-1$, then the borrower would make another payment $P$ at time $T$. If the loan was refinanced at $T-1$, then the borrower would pay points on his loan balance, and would then make a payment of $P^{*}$ at $T$. Alternatively, the borrower may pay off his mortgage for exogenous reasons at $T-1$ in which case he would also pay $L$ at $T-1$ but have no further cash flows in the future. Again, given the decision not to refinance at $T-2$, all future cash flows are determined by the functions $A, B$, and $R^{*}$ determined for $t>T-2$. In exactly the same way, we can also determine all future cash flows that result from a decision to refinance at $T-2$ at the par mortgage rate $R^{*}(D, T-2)$. Finally, in exactly the same manner as before, we regress the ex post discounted cash flows resulting from the two decisions on the same set of functions of $R$ and $D$. The fitted values from these two regressions then become the estimators for the two functions $A(R, D, T-2)$ and $B(R, D, T-2)$. All of the key functions at $T-2$ are now identified.

The algorithm then rolls back to $T-3$, and repeats the same procedure by solving for ex post cash flows, estimating the conditional expectation function through a cross-sectional regression to obtain $V(R, D, T-3)$, solving for $R^{*}(D, T-3)$, and then following a similar procedure to obtain $A(R, D, T-3)$ and $B(R, D, T-3)$. The procedure continues by rolling back one more period and repeating the entire process until the initial date $t=0$. Once completed, this algorithm results in a complete specification of the par mortgage rate $R^{*}(D, t)$ for all $t=0,1, \ldots, 120$. Note that the par mortgage rates are all conditional on the parameter values $\alpha$ and $\lambda$; changing the number of refinancing points or the probability of an exogenous prepayment will alter the par mortgage rates. ${ }^{3}$

${ }^{3}$ Although solving for the par mortgage rate at each date along each path is the most 
Having solved for the par mortgage rate at each date along each path, we can now focus on the valuation of a mortgage where the borrower may only be able to refinance his loan at a premium rate because of his credit. In particular, let $\beta$ denote the credit spread or the difference between the rate at which the borrower can refinance and the par mortgage rate. Let $A_{\beta}(R, D, t)$ denote the present value of the lifetime mortgage costs faced by a borrower with credit spread $\beta$ who does not refinance at time $t$. Similarly, let $B_{\beta}(R, D, t)$ represent the present value of the lifetime mortgage costs faced by the same borrower when he refinances his mortgage at rate $R^{*}(D, t)+\beta$ at time $t .^{4}$

To identify these two present value functions, we follow the same procedure described above to solve for the functions $A(R, D, t)$ and $B(R, D, t)$. The only difference is that the cost of refinancing is higher than before and it is easily seen that $A_{\beta}(R, D, t) \geq A(R, D, t)$ and $B_{\beta}(R, D, t) \geq B(R, D, t)$. Finally, once the functions $A_{\beta}(R, D, t)$ and $B_{\beta}(R, D, t)$ are determined for all $t$, we can solve for the value of the mortgage $V_{\beta}(R, D, t)$ by taking the present value of the cash flows for the mortgage generated by following the stopping or prepayment rule implied by these present value functions and averaging them over all $N$ paths. ${ }^{5}$

It is important to point out that in applying this algorithm to the valuation of mortgage-backed securities throughout this paper, we make the simplifying assumption that all of the borrowers in a mortgage pool are identical. This assumption allows us to treat a mortgage-backed security as if it were a single loan. As shown by Stanton (1995), however, a number of important properties of empirical prepayments such as the burnout effect can be explained by borrower heterogeneity. Although beyond the scope of this paper, we note that it would be straightforward to value a mortgagebacked security with heterogeneous borrowers in our framework. This could be done by simply valuing the cash flows from the individual mortgages in the underlying mortgage pool and then adding up the values.

correct way to proceed, we also find that an alternative specification in which the spread between the par mortgage rate and the ten-year swap rate is assumed to be constant over all paths and dates gives results very close to those reported throughout this paper.

${ }^{4}$ We also explored specifications in which $\beta$ was stochastic rather than constant. The results suggest that only the mean value of $\beta$ has much effect on mortgage-backed security values. Thus, assuming $\beta$ to be constant results in little loss of generality.

${ }^{5}$ Even when $\beta \neq 0$, the cash flows generated by following the stopping rule are discounted using the riskless rate in order to value the mortgage. Thus, we are not actually valuing the mortgage itself, but rather the mortgage with the GNMA guarantee. This is appropriate, however, since our objective is to value mortgage-backed securities, not individual unguaranteed mortgage loans. 
To complete the description of the valuation algorithm, we need to specify the explanatory variables used in the cross-sectional regressions. At each date $t$, there are $N$ simulated paths or realizations of the state vector $D$. To provide a cross-section of values for $R$, we allow $R$ to range from 0.005 to 0.150 in 30 increments of 0.005 . Taking the cross product of these 30 values with the $N$ realizations of $D$ gives us $30 \mathrm{~N}$ realizations of the conditioning variables $R$ and $D$. For each of these $30 N$ realizations, we then determine the present value of the future cash flows generated by following the corresponding optimal stopping rules. Discounting is done using the usual money market compounding factor obtained by rolling over an investment in the short-term discount bond. We then regress these $30 \mathrm{~N}$ values for the discounted future cash flows on ten explanatory variables of the form $R^{i} C^{j}$ where $i$ and $j$ range from 0 to 2 , and $i+j \leq 3$, and where $C$ is the par rate on a fixed coupon bond with ten years until maturity defined by

$$
C=4\left[\frac{1-D(t, t+10)}{\sum_{i=1}^{40} D(t, t+i / 4)}\right] .
$$

The use of the par rate for a fixed coupon bond provides a parsimonious way of capturing the key information in the vector $D$ of discount bond prices since it is directly related to the present value of all remaining contractual payments on the mortgage. ${ }^{6}$ Robustness checks indicate that adding additional regressors to capture higher degree terms has little or no incremental effects on the results. Similarly, more general specifications that include information about other points on the term structure give virtually identical results. Since there is no cross sectional dispersion in the vector $D$ at time zero, it is difficult to identify the present value functions $A$ and $B$ at time zero. For this reason, we make the assumption that the mortgage cannot be immediately prepaid at time zero; that the first time that the loan can be refinanced is after three months. This can be viewed as equivalent to assuming that the mortgage loan application and approval process requires a discrete period of time. Because of this simplifying assumption, the value of a mortgage may exceed 100 slightly even in the absence of transactions costs. Specifically, the amount by which the mortgage value can exceed 100 is the accrual of the difference between the mortgage coupon rate and the short-term rate for one period.

Finally, to keep the numerical implementation of this algorithm tractable, we follow Dunn and Spatt (1986) and Stanton and Wallace (1998) and assume that the mortgage balance at time $t$ is determined by the current mortgage rate $R$ on the loan. In actuality, the balance at time $t$ is path dependent through its dependence on the entire history of the mortgage rates paid by the borrower since the loan was originated.

${ }^{6}$ When $t$ is greater than 20 years, $C$ represents the par rate for a fixed coupon bond with final maturity at 30 years. 
Numerical diagnostics, however, indicate that the effect of this simplifying assumption on mortgage valuation is negligible.

\section{NUMERICAL EXAMPLES}

To illustrate the optimal recursive refinancing model, we implement the algorithm described in the previous section using $N=2,000$ simulated paths of the string market model. Table 1 reports the prices for 30-year mortgage-backed securities for a range of coupon rates and for a variety of mortgage refinancing costs and credit spreads. To provide additional perspective, Table 1 also reports mortgage-backed security values using an extended version of Dunn and McConnell (1981a, b) in which the borrower faces costs of refinancing, but is always able to borrow at the par mortgage rate. This extended model is also implemented by applying the LSM algorithm to the paths generated by the string market model. While calibration will be discussed later, we note at this point that these examples are based on swap market and fixed income option data for June 28, 2002.

Recall that classical optimal prepayment models such as Dunn and McConnell (1981a, b) and Dunn and Spatt (1986) imply that mortgage-backed security values cannot exceed 100 plus the number of points required to refinance the mortgage (plus coupon accrual for one period). As shown in Table 1, the maximum value of the mortgage implied by the extended Dunn and McConnell model is only on the order of 102. Thus, the classical modeling approach clearly cannot capture the level of prices observed in the market which often approaches 110. In contrast, the recursive model is easily able to generate values far in excess of par plus refinancing points (plus coupon accrual for one period). For example, when the borrower faces refinancing costs of two points, the value of a mortgage-backed security reaches a maximum of 105.23 when $\beta=50$ basis points, 110.12 when $\beta=150$ basis points, and 114.29 when $\beta=250$ basis points. This can also be seen in Figure 1 which plots mortgage-backed security values as a function of the coupon rate. Recall that credit spreads as large as 250 basis points are standard in the rapidly growing subprime mortgage market.

Table 1 shows that mortgage-backed security values implied by the optimal recursive model are increasing functions of the number of points associated with refinancing. In general, however, the effect on the price is much less than one-to-one with the number of points for most coupon rates. The exception is for the maximum price which is impacted on roughly a one-to-one basis by the number of financing points. Recall that the recursive model takes into account not just the cost of the next refinancing, but all potential refinancings of the mortgage balance. As shown by Dunn and Spatt (1986) and others, the value of a mortgage-backed security is generally not a monotonic function of the coupon rate. Typically, the price increases above par, reaches a maximum, and then declines as the coupon is increased. Intuitively, this is because the value of a mortgage-backed security must converge to par (plus coupon accrual) 
when the coupon rate is so far above the current par mortgage rate that it is optimal for the borrower to refinance at the next opportunity. Again, this can be seen directly in Figure 1.

To examine how credit risk affects the timing of prepayment within the optimal recursive model, Table 2 reports the mean times to first prepayment for the same examples as those in Table 1. As shown, when the borrower must refinance at a mortgage rate that includes a credit spread, the mean time to the first prepayment date can be many years later than it would be otherwise. For example, when the coupon rate is 7.00 percent and the borrower must pay two points to refinance, the mean time to first prepayment is 7.93 years when $\beta=0$ basis points, but is 12.88 years when $\beta=250$ basis points. The difference in the mean time to first prepayment is even more striking when compared with the measures for the extended Dunn and McConnell (1981a, b) model.

\section{THE DATA}

In conducting this study, we use a number of types of financial data including mortgage rates, term structure data from the Treasury, Agency, Libor, and swap curves, implied volatilities for interest rate caps and swaptions, and indicative data and market prices for GNMA I mortgage-backed securities. All data are obtained from the Bloomberg system which collects and aggregates market quotations from a number of brokers and dealers in the fixed income markets. Except where noted otherwise, all data consist of monthly observations (month-end New York closes) for the June 1992 to June 2002 period.

The interest rate data used in the study includes the par GNMA I mortgage rate, representing the coupon rate at which a newly-originated mortgage-backed security would sell at par in the market. The Treasury data consist of constant maturity 2year, 3-year, 5-year, 7-year, 10-year, 20-year, and 30-year par rates. These constant maturity rates are based on the yields of actively-traded on-the-run Treasury bonds. Similarly, the Agency data consist of constant maturity par rates for the same maturities (beginning in December 1992). These constant maturity Agency par rates are estimated by Bloomberg from the yields of a sample of over 100 noncallable fixed rate bonds issued by agencies such as FNMA and FHLMC. Finally, we include the 3-month Libor rate as well as midmarket 2-year, 3-year, 5-year, 7-year, 10-year, 15-year, 20year, and 30-year par swap rates. ${ }^{7}$ These are the standard maturities for which swap rates are quoted in the market.

To illustrate the data, Table 3 reports summary statistics for the par mortgage rate. Also reported are summary statistics for the spread between the mortgage rate

${ }^{7}$ The 20 -year par swap rate is only available from June 1994 onward. 
and the 10-year Treasury, Agency, and swap rates. Throughout the sample period, the mortgage rate is always higher than either the 10-year Treasury, Agency, or swap rate. This, of course, does not imply that mortgages have more credit risk than reflected in these other curves. Rather, the par mortgage rate is higher because of the prepayment option that the mortgage investor is short. On average, the mortgage rate is 119 basis points higher than the Treasury rate, 72 basis points higher than the Agency rate, and 65 basis points higher than the swap rate. Observe that the spread to the swap rate displays the least serial correlation.

To provide some insight into the behavior of the mortgage rate, Table 4 reports standard deviations for the spread between the mortgage rate and Treasury, Agency, and swap rates for varying maturities. Table 4 also reports the correlations between the mortgage rate and the other rates. The results indicate that of the three curves, mortgage rates are more closely related to swap rates. In particular, the spread between the par mortgage rate and the 10-year swap rate is only 11.9 basis points. Thus, over the 1992 to 2002 sample period, the mortgage rate is very nearly equal to the 10 -year swap rate plus a constant spread of 65 basis points. Similarly, the highest correlations are those between the mortgage rate and the swap rates. For example, the correlation between the mortgage rate and the 10-year swap rate is 0.986 . Because of the close relation between mortgage rates and the swap curve, we use the swap curve as the underlying term structure in implementing the string market model. We note, however, that there are several other reasons for this choice. For example, calibrating the model requires using volatility data for long-dated interest-rate options. The only such data available is for swap-curve-related derivatives like interest rate caps and swaptions. Additionally, although GNMA mortgage-backed securities are backed by the Treasury, recent evidence by Longstaff (2003) shows that other Treasury-backed debt often trades at significantly higher yields than do Treasury bonds. Thus, discounting GNMA cash flows along a curve constructed from on-the-run Treasury bonds may be inappropriate since these bonds can include a significant flight-to-liquidity premium. The last point argues for using the Agency curve, or what is nearly the same, the swap curve as the basis for valuing GNMA mortgage-backed securities.

To implement the string market model, we need to identify the term structure of discount bond prices out to 30 years from the Libor and swap rate data. We do this in the following simple way. First, we use a standard cubic spline algorithm to interpolate the par curve at semiannual intervals. This semiannual frequency corresponds to the frequency with which fixed payments are made on swaps. We then solve for the vector of discount bond prices that correspond to the par curve using the standard bootstrapping procedure. We then obtain quarterly discount bond prices from the bootstrapped semiannual discount bond prices by a simple linear interpolation of the yields to maturity. Table 5 presents summary statistics for the Libor and swap rate data used to generate discount bond prices. Figure 2 plots this term structure data over the sample period. 
The interest-rate cap data consists of monthly implied volatilities for 2-year, 3year, 4-year, 5-year, 7-year, and 10-year caps for the same period as the term structure data. By market convention, the strike price of a $T$-year cap is simply the $T$-year swap rate. The market prices of caps are given by substituting market volatility quotations into the Black (1976) model as described in Longstaff, Santa-Clara, and Schwartz (2001b) and others. To generate a term structure of volatilities for individual forward rates out to 30 years, we do the following. First, since market cap volatilities are only available for horizons out to 10 years, we assume that a 30-year cap would have an implied volatility two-thirds that of the 10-year cap. Although admittedly somewhat arbitrary, this assumption is fairly consistent with the ratio of implied volatilities for long-term and shorter-term swaptions observed in the market. We then use a nonlinear least-squares optimization algorithm to solve for the polynomial of the form $\sum_{j=-2}^{j=2} \alpha_{j} T^{j}$ that provides the best root-mean-squared fit to the prices of all eight of the interest-rate caps. The fitted value of this polynomial is evaluated at quarterly maturities out to 30 years, which is then used as the discretized volatility function $\sigma$ in calibrating the string market model. Table 5 also presents summary statistics for the interest cap data used in the study. Figure 3 plots the time series of the cap volatility term structure.

To calibrate the parameter $\gamma$ governing correlations among individual forward rates, we solve for a value of $\gamma$ approximating the implied correlation matrix for forwards reported in Longstaff, Santa-Clara, and Schwartz (2001b). In their study, Longstaff, Santa-Clara, and Schwartz estimate the correlation matrix for forward rates that best fits a cross section of 34 different European swaptions each week during the 1997 to 1999 period, and report the average correlation matrix across their sample period. We find that $\gamma=.01$ provides a close approximation to the average implied correlation matrix they report. Diagnostic tests, however, indicate that our results are robust across a wide range of values for $\gamma$. We also collected a sample of swaption values from near the end of our sample period and checked whether the swaption values implied by the model using the caplet volatility curve in conjunction with this value of $\gamma$ matched these market values. This diagnostic check indicated that the implied swaption values were generally quite close to the market swaption values. A number of other specifications for the correlation function were investigated but found to perform similarly to the functional form used in this study.

The mortgage-backed security data for the study consist of monthly midmarket quotations for a wide spectrum of GNMA I TBAs (to be announced) with coupons ranging from 5.50 to 9.50 percent in increments of 50 basis points. As described by the Bond Market Association, a TBA is a contract for the purchase or sale of mortgage-backed securities to be delivered at an agreed-upon date in the near future. The specific pool numbers that will be delivered are unknown at the time of the trade, but are required to satisfy standard good delivery guidelines. Thus, TBAs can be viewed as short-term forward trades in generic mortgage-backed securities with a specific coupon. To avoid the possibility of stale prices from illiquid issues, we only 
include TBA prices when the total remaining principal amount of all outstanding GNMA I pools for that coupon exceeds $\$ 250$ million. For the purposes of this study, we consider TBA prices to be equivalent to the market values of newly-originated 30year mortgage loans with the corresponding mortgage rate. In actuality, the weighted average maturities of the loans in GNMA I pools eligible for TBA delivery can be less than 30 years. During the sample period, however, and for the issues included in the data set, the weighted average maturity (WAM) is never less than 26 years. In fact, Table 6 shows that the average WAM is in excess of 28 years for all of the mortgage-backed securities in the sample. Thus, there is little loss of precision from this simplifying assumption. Similarly, the effect on the results of abstracting from the forward settlement feature of TBAs is negligible.

Table 6 also provides descriptive statistics for the mortgage-backed security prices in the sample. As shown, there is significant cross-sectional variation in the prices across coupon rates. Throughout the sample period, the prices range from a low of about 82 to a high of more than 109. This can also be seen directly from Figure 4 which plots the prices during the sample period. As shown, the range of prices near the end of 1994 was nearly twice as large as the range during the middle of 2002 . Interestingly, there is also considerable cross-sectional dispersion in the volatilities of prices. In particular, the standard deviations of the low-coupon mortgage-backed securities are several times as large as those for the high-coupon mortgage-backed securities. One possible reason for this is that the borrower's prepayment option has more of a dampening effect of the prices of premium mortgage-backed securities since it is deeper in the money. The number of observations for the 5.50 percent coupon is 29 , while the number of observations for the 9.50 percent coupon is 52 . The reason for the limited number of observations is the variation in mortgage rates during the sample period. During the early 1990s, mortgage-backed securities with coupons as low as 5.50 percent were rare because par mortgage rates were much higher, and vice versa near the end of the sample period.

Table 7 presents the correlation matrix for the mortgage-backed security prices. As shown, mortgage-backed securities with similar coupons tend to be highly correlated with one another. In contrast, the prices of low- and high-coupon mortgagebacked securities display a significant amount of independent variation. For example, the correlation between the 5.50 and 9.00 percent coupons is only 0.180. Similarly, the correlation between the intermediate 7.00 percent coupon and the high 9.50 percent coupon is 0.720 . In contrast, the correlation between low and medium coupons is generally much higher. This illustrates that the prices of premium mortgage-backed securities tend to be affected by factors that are less prevalent in lower- and mediumcoupon mortgage-backed securities.

As discussed earlier, the possibility that the borrower may have to refinance at an above-market rate because of his financial situation can have a large impact on the optimal recursive strategy. Although the credit of the borrowers in the underlying 
mortgage pools is not completely observable, some information about their financial situation can be inferred from the data available to us. In particular, we can compare the mortgage rate on their current loan with prevailing mortgage rates at the time the mortgage was originated. To illustrate this procedure, consider the following example. At the end of June 2002, the WAM for the 9.00 percent coupon mortgage-backed security was 27 years 6 months, implying that the underlying mortgage loans were 30 months old. Rolling back 30 months to December 1999, we find that the par mortgage rate at that time was 7.83. This implies an estimate of 113 basis points for the spread between the mortgage rate on the loans and the prevailing rate at the time the loans were originated. We repeat this procedure for the entire sample and denote the (positive) differences as credit spreads. We acknowledge, of course, that these estimates doubtlessly contain noise since we can only approximate the origination date of the mortgages from the WAM. Furthermore, there are a number of other factors besides credit which may account for borrowers taking out loans at premium mortgage rates. Despite these limitations, this measure may provide valuable information about the financial situation of borrowers at the time their loans were originated.

In actuality, this measure of the credit spread could be significantly downward biased. For example, assume that the average credit of the set of borrowers who are initially in a high-coupon pool remains the same over time. Individually, however, some borrowers may experience an improvement in their financial situation while others may experience a decline. Borrowers who are able to borrow at a lower credit spread will find it optimal to refinance their loan sooner than those whose credit remains the same or declines. Thus, there may be a reverse survivorship aspect to highcoupon mortgage pools. This argument suggests that the average credit spread for the borrowers within an existing high-coupon mortgage pool may increase significantly over time. This aspect parallels the well-known seasoning or burnout features used to describe empirical prepayment behavior.

Table 8 reports summary statistics for the estimated credit spreads. Figure 5 plots the time series of these credit spreads. As shown, many of the high-coupon observations are associated with significant credit spreads. For example, the average credit spread for the 9.00 percent coupon mortgage-backed security is 82.9 basis points. The average credit spread is almost monotonically increasing with the coupon rate. The only exception is the 9.50 percent mortgage-backed security which has an average credit spread of 68.3 basis points. These results strongly suggest that there may be a significant credit component to many of these high-coupon mortgage-backed securities. Recall from the numerical examples shown in Table 1 that credit spreads on the order of magnitude of those in Table 8 could easily account for prices as high as 107 or 108 . This would be consistent with virtually all of the high-coupon prices in the sample.

It is important to stress that reconciling the premium prices observed in the market within a rational model of refinancing behavior does not require the assumption that credit problems are widespread among borrowers. In fact, the remaining principal 
amount of premium mortgage-backed securities is actually fairly small relative to that for the other mortgage-backed securities. For example, mortgage-backed securities with coupon rates more than 100 basis points above the current mortgage average only about 13.4 percent of the total principal balance of all mortgage-backed securities throughout the sample period. An important implication of these statistics is that a credit-based explanation for the premium prices of high-coupon mortgages may only require that 10 to 15 percent of borrowers face credit spreads in refinancing. Given that subprime mortgage lending now represents more than 13 percent of all mortgage lending, a credit-based explanation of premium mortgage-backed security prices is certainly plausible.

\section{REGRESSION ANALYSIS}

As a preliminary to applying the optimal recursive model to the mortgage-backed security data, it is useful to first examine how prices respond to changes in underlying term structure variables. In an important recent paper, Boudoukh, Whitelaw, Richardson, and Stanton (1997) find that GNMA mortgage-backed security prices are driven by at least two term structure factors. Further, they find evidence of at least one common factor in the GNMA pricing errors from their multivariate density estimation model and consider a number of possible explanations for this finding.

In the spirit of the Boudoukh, Whitelaw, Richardson, and Stanton (1997) analysis, we investigate the factor structure of the GNMA mortgage-backed security prices in the sample. Since this analysis is only intended to be exploratory, however, we adopt the simple approach of regressing changes in prices on changes in three-month Libor, changes in the 10-year and 30-year swap rates, and changes in the average implied volatility of interest rate caps. Although simplistic, this regression approach has the advantage of allowing us to determine the extent to which prices are driven by the various points along the term structure. Furthermore, by including changes in volatility in these regressions, we can examine directly whether volatility-related variation in the value of the prepayment option is a significant determinant of mortgage-backed security price changes.

Table 9 reports the regression results. As shown, all of the variables have explanatory power, at least for some of the coupons. Changes in the three-month Libor rate are significant for the 7.50 through 9.00 percent coupons. Changes in the 10 -year swap rate are significant for the 5.50 through 8.00 percent coupons. Changes in the 30 -year rate are significant for the 6.00 through 7.50 percent coupons. Consistent with Boudoukh, Whitelaw, Richardson, and Stanton (1997), these results indicate the presence of at least three term structure variables driving GNMA mortgage-backed security prices. As shown earlier in Table 2, the higher the coupon rate, the shorter the effective maturity or duration of the mortgage-backed security. The results in Table 9 are consistent with this implication. Specifically, low-coupon mortgage-backed 
securities are more sensitive to longer-term rates, while high-coupon mortgage-backed securities are more sensitive to shorter-term rates.

Table 9 also shows that changes in prices are significantly affected by changes in interest rate volatility. Interestingly, the results are the most significant for the intermediate coupons. This makes intuitive sense since the prepayment option is likely to be deep out of the money for low-coupon mortgages and deep in the money for highcoupon mortgages. Thus, the vega or sensitivity to volatility of the prepayment option should be highest when the mortgage coupon is close to the current par mortgage rate in the market.

These results suggest the presence of at least three term structure factors and one volatility factor driving GNMA prices. The $R^{2}$ s for the regressions are relatively high for the 5.50 through 7.50 percent coupons, implying that most of the variation in their prices is driven by these factors. In contrast, the $R^{2} \mathrm{~s}$ for the high-coupon mortgage-backed securities are much lower, reaching a low of 0.237 for the 9.50 percent coupon. This is consistent with the correlations shown in Table 6 which indicate that there is considerable independent variation in the prices of high-coupon mortgagebacked securities. In summary, these results suggest that the possibility that highcoupon mortgage-backed security prices are influenced by additional factors that have a much smaller effect on low-coupon and medium-coupon mortgage-backed securities. A careful inspection of the numerical results in Table 1 indicates that variation in the credit spread has a disproportionately large effect on the prices of high-coupon mortgage-backed securities. Thus, variation in credit spreads is a potential candidate for explaining the price movements of high-coupon mortgage-backed securities.

\section{EMPIRICAL RESULTS}

In this section, we examine the extent to which market mortgage-backed security prices can be explained by allowing for credit spreads within the recursive framework. In doing this, we use the following four-step approach. First, we assume that the number of refinancing points $\alpha$ is fixed at two points throughout the sample. ${ }^{8}$ Second, we solve for the parameter $\lambda$ that provides the best root-mean-squared fit to the vector of discount mortgage-backed security prices each month. Third, for each premium mortgage-backed security price in the sample, we solve for the implied credit spread that allows the calibrated model to match that market price. Finally, we examine whether these implied credit spreads are consistent with the empirical properties of credit-related measures for the individual mortgage-backed securities.

${ }^{8}$ The assumption that transaction costs average two points is consistent with a number of industry sources. We note, however, that the results are fairly insensitive to modest variation in this parameter. 
To be specific, for each of the 121 months in the sample, we generate 1,000 paths of the string market model using the corresponding vectors of discount bond prices and caplet volatilities. For each month, we then solve for the value of $\lambda$ that best fits the mortgage-backed securities with prices less than 100. In doing this, we make the realistic identifying assumption that borrowers in these low-coupon mortgage pools could refinance at the par mortgage rate. Typically, there are two to four discount mortgage-backed securities each month from which $\lambda$ can be estimated. For the few months where there are no discount mortgage-backed securities, we use the parameter $\lambda$ from the previous month as the estimated value of $\lambda$. We use a standard numerical search algorithm to solve for the value of $\lambda$ that best fits the discount mortgage-backed security prices. Alternative algorithms result in similar estimates. Table 10 reports summary statistics for the fitting procedure and the estimated values of $\lambda$. As shown, the model achieves a close fit to the prices of the discount mortgage-backed securities in the sample. Across the 121 months in the sample, the average root-mean-squared error is only 0.22 per $\$ 100$ principal amount, while the median root-mean-squared error is only 0.16 per $\$ 100$ principal amount. These pricing errors are only slightly larger than the typical bid-ask spread for these securities.

The summary statistics for the turnover parameter $\lambda$ show that the average implied probability that a borrower will pay off his loan for exogenous reasons is 5.59 percent per year. The median probability of an exogenous payoff is 5.15 percent per year. To provide historical perspective, it is interesting to contrast these implied turnover probabilities with actual turnover statistics. To do this, we collect data on the seasonally adjusted number of sales of existing single-family homes in the U.S. from the National Association of Realtors for each month during the sample period. We also collect data on the number of single-family homes in the U.S. from Hayre (2001) and the U.S. Census Bureau. Linearly interpolating the annual housing stock data to provide monthly estimates, we estimate the historical actual turnover frequency by dividing the number of sales by the housing stock. As shown in Table 10, the mean value for the actual turnover frequency is 6.04 percent, which is only slightly higher than the mean implied frequency. Figure 6 plots the time series of the implied and actual turnover frequencies. As can be seen, the implied turnover frequency closely approximates the actual turnover frequency in its level. Furthermore, the implied value is clearly correlated with the actual turnover ratio. Table 10 reports that the correlation between the two turnover measures is 0.327 . Although this correlation is far from perfect, recall that the actual turnover measure only captures the current month's experience while the implied turnover parameter reflects the market's forecast over the entire future life of the mortgage. In light of this, this correlation is surprisingly high. These results indicate that mortgage-backed security prices contain significant information about the propensity of borrowers to sell their homes and pay off their mortgages for exogenous reasons. Further, the recursive model is able to extract this information from market prices. 
Recall that the par mortgage rate is endogenously determined in the recursive model. Specifically, at each date along each of the simulated paths of the term structure, the model solves for the coupon rate at which a newly-issued 30-year mortgage would sell for par. To provide additional insight into the model, we solve for the initial or time-zero par mortgage rate implied by the model and contrast it with the actual GNMA I par mortgage rates during the sample period. Rather than reporting these rates in their levels, Table 10 reports summary statistics for the spread between the rates and the 10-year swap rate. As illustrated, the average par mortgage spread implied by the recursive model almost matches the actual par mortgage spread exactly. In particular, the average implied spread is 70 basis points over the 10 -year swap rate while the average historical spread is 65 basis points over the 10 -year swap rate. Both the implied and actual spreads have a median value of 65 basis points. The correlation between the two time series is very high; Table 10 shows that the correlation between the implied and actual spreads is 0.686 . Figure 7 plots the time series of the implied and actual credit spreads. Together with the previous results, this evidence indicates that the recursive model is successful in capturing the properties of both discount and par mortgage-backed securities during the sample period.

Turning now to the valuation of premium mortgage-backed securities, we use the model to solve for the implied credit spread for each premium mortgage-backed security in the sample. Specifically, for each month, we use the simulated paths and the implied value of $\lambda$ for that month to generate model prices for a grid of different credit spreads or values of $\beta$. From this grid, we then solve for the value of $\beta$ that that matches the market price of each mortgage-backed security to its model value. Note that this procedure allows each premium mortgage-backed security to be fit exactly since each mortgage-backed security has its own implied credit spread. Of course, by fitting the data exactly, we cannot use goodness of fit measures to evaluate the model's performance. Rather, our approach is to examine whether the implied credit spreads from the model are consistent with empirical measures of borrower credit. It is important to observe, however, that the ability of the recursive model to match premium prices is not trivial. As discussed, previous optimal prepayment models do not allow prices to exceed par plus the number of refinancing points. Thus, previous optimal prepayment models would be unable to match the majority of the premium prices in the sample.

Table 11 reports summary statistics for the implied credit spreads. Figure 8 graphs the time series of implied credit spreads. As shown, the credit premia needed to match the premium mortgage-backed security prices in the sample are relatively small. For example, Table 6 shows that the average price of the high-coupon 9.00 percent mortgage-backed securities in the sample is 105.56. Table 11 shows that the average implied credit premium for these mortgage-backed securities is 119.2 basis points, or only slightly more than 1 percent. Recall from the earlier discussion that the average subprime mortgage rate near the end of the sample period is approximately 300 basis points in excess of the par mortgage rate. The implied credit spreads from 
the recursive model are clearly well within this range for all of the coupon rates in the sample. The average implied credit spreads are monotonic in the coupon rate.

As illustrated in Table 8, many of the high-coupon mortgages in the sample were originated at rates exceeding the prevailing par mortgage rate in the market at the time of origination. As discussed earlier, one reason for this could be that these borrowers might not have been able to satisfy the strictest underwriting guidelines and, therefore, had to pay a premium rate to obtain a FHA or VA mortgage. Over time, borrowers whose financial situation improves would be able to refinance at a lower credit spread. Thus, as time passes, we might expect that the average credit quality of the remaining borrowers underlying a premium mortgage-backed security would tend to decrease. This would imply that implied credit spread for a mortgage-backed security could be somewhat wider than the credit spread for the mortgage-backed security at the date of origination.

This hypothesis is easily investigated by comparing the average credit spreads at origination shown in Table 8 with the average credit spreads implied by the recursive model shown in Table 11. As can be seen, the original and implied credit spreads are actually very similar for the mortgage-backed securities with coupons ranging from 5.50 to 8.50 percent. For example, the original credit spreads for the 7.50 and 8.00 percent mortgage-backed securities are 23.9 and 34.6 basis point respectively. These closely match the average implied credit spreads for these coupons of 21.1 and 45.7 basis points respectively. For the remaining coupons, the implied credit spread is somewhat larger than the original credit spread. For example, the average original credit spread for the 9.00 percent coupon mortgage-backed security is 82.9 basis points, which is roughly 70 percent of the average implied credit spread. In general, however, the implied credit spreads closely track the credit spreads at the origination date of the mortgages. This provides indirect evidence that the recursive model captures the economics of premium mortgage-backed security prices, since the original credit spread is not used in calibrating the model.

To examine more directly whether implied credit spreads reflect borrower fundamentals, we investigate the relation between these spreads and the credit quality of the borrowers whose mortgages underlie the mortgage-backed security. Of course, detailed information about individual borrowers' financial situations is not directly observable. Despite this, however, there are several instrumental variables which may proxy for borrower credit quality. The first of these is simply the original credit spread or difference between the mortgage coupon rate and the prevailing par mortgage rate at the time that the mortgages were originated. As discussed above, this variable may reflect the average credit quality of the borrowers at the origination date of the mortgage loans. As a second proxy, we use the percentage of the original principal balance that has been paid off. Recall from Table 6 that the typical mortgage-backed security in the sample is based on a pool of mortgages that are one to two years old. During this oneto two-year period, some of the individual borrowers with high-coupon mortgages may 
find that their financial situation has improved. These borrowers have strong incentives to prepay and refinance their loans. Thus, over time, the average credit quality of the borrowers remaining in a premium pool may decrease as higher-credit borrowers exit the pool. Because of this, the percentage of the original principal balance that has been paid off may contain information about the average credit quality of borrowers underlying an mortgage-backed security.

Table 12 reports the results from regressions of the implied credit spread on the original credit spread and the percentage prepaid. As illustrated, both of the proxies for borrower credit risk have significant explanatory power for the implied credit spread. In particular, the $t$-statistics for the two variables are 10.62 and 10.79 respectively. The sign of the regression coefficient is positive for both variables. Thus, the implied credit spread is an increasing function of the original credit spread. This is consistent with the view that the original credit spread directly reflects the average credit of the borrowers in the mortgage pool. Similarly, the positive sign for the percentage prepaid variable is consistent with the interpretation that the average credit quality of a premium mortgage pool deteriorates over time as the better credits in the pool prepay. Although these two variables are only proxies for credit risk, their explanatory power for the implied credit spread is very high since the $R^{2}$ for the regression is 0.373 . Each of the two explanatory variables is also significant in individual univariate regressions. This is illustrated in Figure 9 which presents scatterdiagrams of the implied credit spread against the individual explanatory variables. As illustrated, there is a strong correlation between the implied credit spread and both explanatory variables. The correlation between the implied credit spread and the original credit spread is 0.488 . The correlation between the implied credit spread and the percentage prepaid is 0.493. These results provide strong support for the hypothesis that the credit spread implied by the recursive model captures fundamental information about the average credit quality of the borrowers underlying the mortgage-backed securities in the sample.

\section{MODEL PERFORMANCE}

In this section, we examine how well the model performs using only ex ante information to price the cross-section of mortgage-backed securities. This out-of-sample test provides insights into the ability of the model to capture the dynamic behavior of mortgage-backed security prices.

In applying the recursive model to mortgage-backed security prices at date $t$, we do the following. First, we assume that the probability of an exogenous payoff is a constant six percent throughout the sample period. Second, for each mortgagebacked security, we use the implied credit spread estimated the previous month for the corresponding coupon rate as the estimate of the credit spread for the current month. Implicit in this approach is the assumption that the credit status of borrowers within 
a specific mortgage pool does not change rapidly, and, therefore, that their credit spread displays some degree of persistence. Given this parameterization, we solve for the mortgage-backed security values for each coupon given by the model and compare them with the actual market prices. The pricing error is the difference between the actual market price and the price implied by the recursive model.

Table 13 reports summary statistics for the pricing errors from the recursive model. Over all coupon rates, the average pricing error is only about 3.6 cents per $\$ 100$ notional or principal amount, and is not statistically significant. The overall root-mean-squared error is 0.858. Although this root-mean-squared error indicates that the recursive model does not fully explain the pricing of all mortgage-backed securities, it is important to observe that the model is able to capture 97.1 percent of the variation in the mortgage-backed security prices during the sample period.

Table 13 also shows that there some residual bias in the pricing for the individual coupons. In particular, the mean errors for the lower-coupon mortgage-backed securities in the sample are all significantly negative, while the reverse is true for the highcoupon mortgage-backed securities. Thus, the model tends to overprice low-coupon mortgage-backed securities and underprice high-coupon mortgage-backed securities. The mean errors, however, are generally less than 50 cents per $\$ 100$ notional amount. Thus, even for the high-coupon 9.50 percent mortgage-backed securities, the recursive model is able to explain nearly 91 percent of the average premium over par. Similarly, the model is able to explain about 94.4 percent of the premium over par for the 9.00 coupon mortgage-backed securities. These results suggest that the recursive model performs well out of sample in explaining the pricing of mortgage-backed securities over the past decade.

\section{CONCLUSION}

This paper studies the optimal recursive refinancing problem for a borrower who faces transaction costs and may have to refinance at a premium rate because of his credit. This paper also examines the implications of the model for the valuation of mortgagebacked securities. We show that the optimal recursive strategy can be very different from that implied by the earlier optimal prepayment models in the literature. In particular, the borrower often finds it optimal to delay prepayment far beyond the point at which these traditional models imply that the mortgage should be prepaid. Because of this key feature, the recursive model can generate mortgage-backed security values that are much higher than those implied by traditional models.

We apply the optimal recursive model to an extensive cross section of mortgagebacked security prices covering a ten-year sample period. We find that the model is able to match the market values of premium mortgage-backed securities using moderate and realistic assumptions about the transaction costs associated with refinancing 
and the credit spreads faced by borrowers. To our knowledge, this recursive refinancing model is the first framework based on rational or optimal prepayment behavior that is able to do so. The results of this study strongly suggest that optimal recursive models offer a promising alternative to the reduced-form or behavioral prepayment models widely used in practice. 


\section{REFERENCES}

Boudoukh, Jacob, Robert. F. Whitelaw, Matthew Richardson, and Richard Stanton, 1997, Pricing Mortgage-Backed Securities in a Multifactor Interest Rate Environment: A Multivariate Density Estimation Approach, The Review of Financial Studies 10, 405-446.

Black, Fischer, 1976, The Pricing of Commodity Contracts, The Journal of Financial Economics 3, 167-179.

Brace, A., D. Gatarek, and M. Musiela, 1997, The Market Model of Interest Rate Dynamics, Mathematical Finance 7, 127-155.

Brennan, Michael J., and Eduardo S. Schwartz, 1985, Determinants of GNMA Mortgage Prices, Journal of the American Real Estate and Urban Economics Association 13, 209-228.

Chari, V. V., and Ravi Jagannathan, 1989, Adverse Selection in a Model of Real Estate Lending, The Journal of Finance 44, 499-508.

Cox, John C., Jonathan E. Ingersoll, and Stephen A. Ross, 1985, A Theory of the Term Structure of Interest Rates, Econometrica 50, 363-384.

Downing, Chris, Richard Stanton, and Nancy Wallace, 2002, An Empirical Test of a Two-Factor Mortgage Prepayment and Valuation Model: How Much Do House Prices Matter?, Working paper, University of California at Berkeley.

Dunn, Kenneth B., and John J. McConnell, 1981a, A Comparison of Alternative Models for Pricing GNMA Mortgage-Backed Securities, The Journal of Finance 36, 471-484.

Dunn, Kenneth B., and John J. McConnell, 1981b, Valuation of GNMA MortgageBacked Securities, The Journal of Finance 36, 599-616.

Dunn, Kenneth B., and Kenneth J. Singleton, 1983, An Empirical Analysis of the Pricing of Mortgage-Backed Securities, The Journal of Finance 38, 613-623.

Dunn, Kenneth B., and Chester S. Spatt, 1985, An Analysis of Mortgage Contracting: Prepayment Penalties and the Due-on-Sale Clause, The Journal of Finance 40, 293308.

Dunn, Kenneth B., and Chester S. Spatt, 1986, The Effect of Refinancing Costs and Market Imperfections on the Optimal Call Strategy and the Pricing of Debt Contracts, Working paper, Carnegie-Mellon University.

Dunn, Kenneth B., and Chester S. Spatt, 1988, Private Information and Incentives: Implications for Mortgage Contract Terms and Pricing, Journal of Real Estate Finance 
and Economics 1, 47-60.

Dunn, Kenneth B., and Chester S. Spatt, 1999, Call Options, Points, and Dominance Restrictions on Debt Contracts, Journal of Finance 59, 2317-2337.

Han, Bing, 2002, Stochastic Volatilities and Correlations of Bond Yields, Working paper, UCLA.

Hayre, Lahkbir, 2001, Salomon Smith Barney Guide to Mortgage-Backed and AssetBacked Securities, John Wiley \& Co., New York, NY.

Hayre, Lahkbir, and Robert Young, 2001, Anatomy of Prepayments, The Salomon Smith Barney Prepayment Model, in Salomon Smith Barney Guide to MortgageBacked and Asset-Back Securities, ed. Lakhbir Hayre, John Wiley \& Co., New York, NY.

Heath, D., R. Jarrow, and A. Morton, 1992, Bond Pricing and the Term Structure of Interest Rates, Econometrica 60, 77-106.

Johnston, Elizabeth T., and L. Van Drunen, 1988, Pricing Mortgage Pools with Heterogeneous Mortgages: Empirical Evidence, Working paper, The University of Utah.

Laderman, Elizabeth, 2001, Subprime Mortgage Lending and the Capital Markets, Federal Reserve Bank of San Francisco Economic Letter, Number 2001-38, December $28,2001$.

Leroy, Stephen F., 1996, Mortgage Valuation Under Optimal Prepayment, The Review of Financial Studies 9, 817-844.

Longstaff, Francis A., 2003, The Flight-to-Liquidity Premium in U.S. Treasury Bond Prices, Journal of Business, forthcoming.

Longstaff, Francis A., and Eduardo S. Schwartz, 2001, Valuing American Options by Simulation: A Simple Least Squares Approach, The Review of Financial Studies 14, 113-147.

Longstaff, Francis A., Pedro Santa-Clara, and Eduardo S. Schwartz, 2001a, Throwing Away a Billion Dollars: The Cost of Suboptimal Exercise Strategies in the Swaptions Market, Journal of Financial Economics 62, 39-66.

Longstaff, Francis A., Pedro Santa-Clara, and Eduardo S. Schwartz, 2001b, The Relative Valuation of Caps and Swaptions: Theory and Empirical Evidence, The Journal of Finance 56, 2067-2109.

McConnell, John J., and Manoj Singh, 1994, Rational Prepayments and the Valuation of Collateralized Mortgage Obligations, The Journal of Finance 49, 891-921. 
Santa-Clara, Pedro, and Didier Sornette, 2001, The Dynamics of the Forward Interest Rate Curve with String Shocks, The Review of Financial Studies 14, 149-185.

Schwartz, Eduardo S., and Walter N. Torous, 1989, Prepayment and the Valuation of Mortgage-Backed Securities, The Journal of Finance 44, 375-392.

Schwartz, Eduardo S., and Walter N. Torous, 1992, Prepayment, Default, and the Valuation of Mortgage Pass-through Securities, Journal of Business 65, 221-239.

Schwartz, Eduardo S., and Walter N. Torous, 1993, Mortgage Prepayment and Default Decisions: A Poisson Regression Approach, Journal of the American Real Estate and Urban Economics Association 21, 431-449.

Stanton, Richard, 1995, Rational Prepayment and the Valuation of Mortgage-Backed Securities, The Review of Financial Studies 8, 677-708.

Stanton, Richard, and Nancy Wallace, 1998, Mortgage Choice: What's the Point?, Real Estate Economics 26, 173-205.

Timmis, G. C., 1985, Valuation of GNMA Mortgage-Backed Securities with Transaction Costs, Heterogeneous Households and Endogenously Generated Prepayment Rates, Working paper, Carnegie-Mellon University. 
Table 1

Mortgage-Backed Security Values Implied by the Optimal Recursive Refinancing Model. This table presents 30-year mortgage-backed security values for the indicated parameters. Credit spread is the number of basis points over the par mortgage rate at which the mortgage could be refinanced. Points represents the percentage costs of refinancing. The model is calibrated to the June 282002 swap curve and interest rate cap and swaption volatilities. Values are based on a par value of 100 . The probability of an exogenous payoff is $6 \%$ per year. The static model is an extended version of Dunn and McConnell (1981a, b) with refinancing points but without credit spreads.

\begin{tabular}{|c|c|c|c|c|c|c|c|c|c|}
\hline \multirow[b]{2}{*}{ Model } & \multirow{2}{*}{$\begin{array}{l}\text { Credit } \\
\text { Spread }\end{array}$} & \multirow{2}{*}{$\begin{array}{r}\text { Refinancing } \\
\text { Points }\end{array}$} & \multicolumn{7}{|c|}{ Coupon Rate } \\
\hline & & & 4.00 & 5.00 & 6.00 & 7.00 & 8.00 & 9.00 & 10.00 \\
\hline \multirow[t]{3}{*}{ Static } & - & 0 & 88.85 & 94.79 & 99.43 & 101.17 & 101.52 & 101.77 & 102.02 \\
\hline & & 1 & 88.86 & 94.84 & 99.57 & 101.34 & 101.52 & 101.77 & 102.02 \\
\hline & & 2 & 88.92 & 94.86 & 99.85 & 101.67 & 101.52 & 101.77 & 102.14 \\
\hline \multirow[t]{3}{*}{ Recursive } & 0 & 0 & 89.01 & 95.00 & 100.03 & 102.49 & 101.63 & 101.79 & 102.03 \\
\hline & & 1 & 89.07 & 95.07 & 100.30 & 103.20 & 101.69 & 101.80 & 102.03 \\
\hline & & 2 & 89.08 & 95.12 & 100.56 & 103.81 & 102.02 & 101.82 & 102.03 \\
\hline \multirow[t]{3}{*}{ Recursive } & 50 & 0 & 89.11 & 95.15 & 100.73 & 104.31 & 102.66 & 101.83 & 102.03 \\
\hline & & 1 & 89.13 & 95.31 & 100.94 & 104.75 & 103.50 & 101.90 & 102.04 \\
\hline & & 2 & 89.17 & 95.40 & 101.10 & 105.23 & 104.86 & 101.99 & 102.04 \\
\hline \multirow[t]{3}{*}{ Recursive } & 100 & 0 & 89.19 & 95.49 & 101.29 & 105.51 & 106.10 & 102.06 & 102.05 \\
\hline & & 1 & 89.21 & 95.62 & 101.44 & 105.99 & 107.15 & 102.25 & 102.07 \\
\hline & & 2 & 89.26 & 95.72 & 101.56 & 106.32 & 108.19 & 102.70 & 102.08 \\
\hline \multirow[t]{3}{*}{ Recursive } & 150 & 0 & 89.28 & 95.78 & 101.65 & 106.62 & 108.82 & 103.81 & 102.09 \\
\hline & & 1 & 89.32 & 95.85 & 101.84 & 106.96 & 109.53 & 105.07 & 102.13 \\
\hline & & 2 & 89.34 & 95.89 & 102.00 & 107.22 & 110.12 & 106.59 & 102.23 \\
\hline \multirow[t]{3}{*}{ Recursive } & 200 & 0 & 89.35 & 95.94 & 102.16 & 107.52 & 110.59 & 107.98 & 102.33 \\
\hline & & 1 & 89.43 & 96.00 & 102.33 & 107.80 & 111.23 & 109.62 & 102.48 \\
\hline & & 2 & 89.44 & 96.04 & 102.51 & 108.02 & 111.82 & 110.94 & 102.81 \\
\hline \multirow[t]{3}{*}{ Recursive } & 250 & 0 & 89.45 & 96.08 & 102.61 & 108.22 & 112.17 & 111.84 & 103.41 \\
\hline & & 1 & 89.48 & 96.15 & 102.75 & 108.41 & 112.67 & 113.18 & 104.25 \\
\hline & & 2 & 89.51 & 96.20 & 102.82 & 108.63 & 113.10 & 114.29 & 105.98 \\
\hline
\end{tabular}


Table 2

Mean Time until First Prepayment Implied by the Optimal Recursive Refinancing Model. This table reports the expected number of years until the first prepayment of a 30-year mortgage. Credit spread is the number of basis points over the par mortgage rate at which the mortgage could be refinanced. Points represents the percentage costs of refinancing. The model is calibrated to the June 28,2002 swap curve and interest rate cap and swaption volatilities. The probability of an exogenous payoff is 6\% per year. The static model is an extended version of Dunn and McConnell (1981a, b) with refinancing points but without credit spreads.

\begin{tabular}{|c|c|c|c|c|c|c|c|c|c|}
\hline \multirow[b]{2}{*}{ Model } & \multirow{2}{*}{$\begin{array}{l}\text { Credit } \\
\text { Spread }\end{array}$} & \multirow{2}{*}{$\begin{array}{r}\text { Refinancing } \\
\text { Points }\end{array}$} & \multicolumn{7}{|c|}{ Coupon Rate } \\
\hline & & & 4.00 & 5.00 & 6.00 & 7.00 & 8.00 & 9.00 & 10.00 \\
\hline \multirow[t]{3}{*}{ Static } & - & 0 & 12.55 & 10.50 & 6.46 & 0.73 & 0.25 & 0.25 & 0.25 \\
\hline & & 1 & 12.91 & 11.22 & 8.76 & 1.72 & 0.25 & 0.25 & 0.25 \\
\hline & & 2 & 13.16 & 11.91 & 9.73 & 2.95 & 0.26 & 0.25 & 0.27 \\
\hline \multirow[t]{3}{*}{ Recursive } & 0 & 0 & 13.26 & 12.20 & 10.18 & 5.10 & 0.53 & 0.37 & 0.25 \\
\hline & & 1 & 13.48 & 12.43 & 10.65 & 6.70 & 0.78 & 0.27 & 0.25 \\
\hline & & 2 & 13.64 & 12.64 & 11.03 & 7.93 & 1.17 & 0.30 & 0.25 \\
\hline \multirow[t]{3}{*}{ Recursive } & 50 & 0 & 13.65 & 12.73 & 11.26 & 8.68 & 2.05 & 0.31 & 0.26 \\
\hline & & 1 & 13.74 & 12.95 & 11.61 & 9.30 & 2.97 & 0.40 & 0.26 \\
\hline & & 2 & 13.84 & 13.13 & 11.93 & 9.85 & 4.59 & 0.49 & 0.26 \\
\hline \multirow[t]{3}{*}{ Recursive } & 100 & 0 & 13.86 & 13.19 & 12.14 & 10.06 & 5.79 & 0.56 & 0.27 \\
\hline & & 1 & 13.97 & 13.39 & 12.35 & 10.56 & 6.88 & 0.78 & 0.29 \\
\hline & & 2 & 14.04 & 13.59 & 12.50 & 10.85 & 7.78 & 1.11 & 0.29 \\
\hline \multirow[t]{3}{*}{ Recursive } & 150 & 0 & 14.04 & 13.60 & 12.62 & 11.05 & 8.29 & 1.96 & 0.30 \\
\hline & & 1 & 14.09 & 13.72 & 12.86 & 11.46 & 8.99 & 2.74 & 0.35 \\
\hline & & 2 & 14.15 & 13.79 & 13.04 & 11.68 & 9.44 & 3.84 & 0.41 \\
\hline \multirow[t]{3}{*}{ Recursive } & 200 & 0 & 14.13 & 13.80 & 13.11 & 11.91 & 9.68 & 4.66 & 0.47 \\
\hline & & 1 & 14.27 & 13.93 & 13.27 & 12.17 & 10.16 & 5.84 & 0.56 \\
\hline & & 2 & 14.31 & 14.01 & 13.48 & 12.37 & 10.54 & 6.75 & 0.79 \\
\hline \multirow[t]{3}{*}{ Recursive } & 250 & 0 & 14.28 & 13.99 & 13.50 & 12.47 & 10.70 & 7.22 & 1.06 \\
\hline & & 1 & 14.33 & 14.08 & 13.68 & 12.69 & 11.06 & 8.09 & 1.51 \\
\hline & & 2 & 14.38 & 14.16 & 13.76 & 12.88 & 11.37 & 8.80 & 2.41 \\
\hline
\end{tabular}


Table 3

Summary Statistics for the Par Mortgage Rate and its Spread to 10-Year Treasury, Agency, and Swap Rates. This table reports summary statistics for the par GNMA I mortgage rate and its spread to the indicated 10-year rates. The data are monthly from June 1992 to June 2002, except for the 10-year Agency rate series which begins in December 1992.

\begin{tabular}{|c|c|c|c|c|c|c|}
\hline & Average & Minimum & Median & Maximum & $\begin{array}{r}\text { Serial } \\
\text { Correlation }\end{array}$ & $\begin{array}{r}\text { Number of } \\
\text { Observations }\end{array}$ \\
\hline Par Mortgage Rate & 7.22 & 5.58 & 7.24 & 8.97 & 0.927 & 121 \\
\hline Spread to 10 -Year Treasury Rate & 1.19 & 0.52 & 1.14 & 2.01 & 0.732 & 121 \\
\hline Spread to 10-Year Agency Rate & 0.72 & 0.43 & 0.75 & 1.00 & 0.845 & 115 \\
\hline Spread to 10-Year Swap Rate & 0.65 & 0.34 & 0.65 & 0.92 & 0.719 & 121 \\
\hline
\end{tabular}




\section{Table 4}

Standard Deviations for Mortgage Spreads and Correlations with Treasury, Agency, and Swap Rates. This table reports the standard deviation of the spread between the par GNMA I mortgage rate and Treasury, Agency, and swap rates of the indicated maturities. Also reported are the correlations between the par mortgage rates and the Treasury, Agency, and swap rates of the indicated maturities. The data are monthly from June 1992 to June 2002, with the exception of several Agency and Treasury series which begin one to two years later.

\begin{tabular}{|c|c|c|c|c|c|c|c|}
\hline & & & & Maturity & & & \\
\hline & 2 & 3 & 5 & 7 & 10 & 20 & 30 \\
\hline $\begin{array}{l}\text { Std. Deviation of Mortgage-Treasury Spread } \\
\text { Std. Deviation of Mortgage-Agency Spread } \\
\text { Std. Deviation of Mortgage-Swap Spread }\end{array}$ & $\begin{array}{l}0.677 \\
0.611 \\
0.714\end{array}$ & $\begin{array}{l}0.516 \\
0.454 \\
0.513\end{array}$ & $\begin{array}{l}0.306 \\
0.215 \\
0.266\end{array}$ & $\begin{array}{l}0.239 \\
0.132 \\
0.148\end{array}$ & $\begin{array}{l}0.313 \\
0.149 \\
0.119\end{array}$ & $\begin{array}{l}0.315 \\
0.279 \\
0.123\end{array}$ & $\begin{array}{l}0.495 \\
0.325 \\
0.289\end{array}$ \\
\hline $\begin{array}{l}\text { Correlation of Mortgage and Treasury Rates } \\
\text { Correlation of Mortgage and Agency Rates } \\
\text { Correlation of Mortgage and Swap Rates }\end{array}$ & $\begin{array}{l}0.799 \\
0.841 \\
0.794\end{array}$ & $\begin{array}{l}0.866 \\
0.902 \\
0.865\end{array}$ & $\begin{array}{l}0.938 \\
0.968 \\
0.950\end{array}$ & $\begin{array}{l}0.953 \\
0.985 \\
0.981\end{array}$ & $\begin{array}{l}0.916 \\
0.979 \\
0.986\end{array}$ & $\begin{array}{l}0.907 \\
0.924 \\
0.988\end{array}$ & $\begin{array}{l}0.775 \\
0.896 \\
0.917\end{array}$ \\
\hline
\end{tabular}


Table 5

Summary Statistics for the Swap Curve and the Implied Volatilities of Interest Rate Caps. This table presents summary statistics for the indicated maturity Libor and swap rates. Also reported are summary statistics for the midmarket Black-model implied volatilities of at-the-money Libor caps. The data are monthly for the period from June 1992 to June 2002.

\begin{tabular}{|c|c|c|c|c|c|c|}
\hline & Average & Minimum & Median & Maximum & $\begin{array}{l}\text { Standard } \\
\text { Deviation }\end{array}$ & $\begin{array}{r}\text { Serial } \\
\text { Correlation }\end{array}$ \\
\hline 3-Month Libor & 4.933 & 1.850 & 5.500 & 6.844 & 1.352 & 0.980 \\
\hline 2-Year Swap Rate & 5.574 & 2.822 & 5.875 & 8.135 & 1.135 & 0.960 \\
\hline 3-Year Swap Rate & 5.831 & 3.420 & 5.945 & 8.195 & 0.988 & 0.948 \\
\hline 5-Year Swap Rate & 6.169 & 4.172 & 6.215 & 8.175 & 0.827 & 0.934 \\
\hline 7-Year Swap Rate & 6.372 & 4.571 & 6.325 & 8.215 & 0.761 & 0.929 \\
\hline 10-Year Swap Rate & 6.567 & 4.899 & 6.565 & 8.275 & 0.717 & 0.926 \\
\hline 15-Year Swap Rate & 6.678 & 5.264 & 6.810 & 8.390 & 0.688 & 0.929 \\
\hline 20-Year Swap Rate & 6.817 & 5.419 & 6.880 & 8.490 & 0.700 & 0.941 \\
\hline 30-Year Swap Rate & 6.925 & 5.513 & 6.980 & 8.500 & 0.693 & 0.945 \\
\hline 1-Year Cap Volatility & 18.64 & 7.75 & 17.50 & 43.12 & 7.83 & 0.933 \\
\hline 2-Year Cap Volatility & 20.34 & 11.10 & 20.05 & 40.00 & 5.94 & 0.923 \\
\hline 3-Year Cap Volatility & 20.29 & 12.60 & 19.80 & 34.20 & 4.40 & 0.913 \\
\hline 4-Year Cap Volatility & 19.82 & 13.40 & 19.75 & 30.50 & 3.51 & 0.905 \\
\hline 5-Year Cap Volatility & 19.32 & 13.50 & 19.25 & 28.80 & 2.98 & 0.897 \\
\hline 7-Year Cap Volatility & 18.24 & 13.50 & 18.20 & 26.00 & 2.46 & 0.887 \\
\hline 10-Year Cap Volatility & 17.13 & 12.30 & 17.10 & 24.00 & 2.21 & 0.898 \\
\hline
\end{tabular}




\section{Table 6}

Summary Statistics for GNMA I Mortgage-Backed Security Prices. This table reports summary statistics for the market prices of GNMA I mortgage-backed security TBAs with the indicated coupon rates. Mortgage-backed securities where the total notional outstanding in all pools is less than $\$ 250$ million are omitted from the sample. Average WAM is the time series average of the weighted average maturity in years of all mortgages in pools with the indicated coupon rates. The data are monthly for the period from June 1992 to June 2002.

\begin{tabular}{|c|c|c|c|c|c|c|c|}
\hline Coupon Rate & Average & Minimum & Median & Maximum & $\begin{array}{l}\text { Standard } \\
\text { Deviation }\end{array}$ & $\begin{array}{l}\text { Average } \\
\text { WAM }\end{array}$ & $\begin{array}{r}\text { Number of } \\
\text { Observations }\end{array}$ \\
\hline 5.50 & 95.20 & 89.36 & 95.55 & 99.77 & 2.27 & 28.8 & 29 \\
\hline 6.00 & 93.95 & 82.27 & 94.19 & 101.73 & 4.40 & 28.6 & 104 \\
\hline 6.50 & 96.68 & 85.67 & 97.27 & 103.33 & 3.95 & 28.7 & 111 \\
\hline 7.00 & 98.89 & 88.84 & 99.22 & 104.41 & 3.37 & 28.7 & 120 \\
\hline 7.50 & 100.92 & 92.05 & 101.35 & 105.42 & 2.82 & 28.1 & 121 \\
\hline 8.00 & 102.66 & 95.05 & 102.89 & 106.42 & 2.29 & 28.6 & 121 \\
\hline 8.50 & 104.24 & 97.83 & 104.45 & 107.48 & 1.88 & 28.3 & 121 \\
\hline 9.00 & 105.56 & 100.50 & 105.84 & 108.16 & 1.58 & 28.4 & 115 \\
\hline 9.50 & 107.42 & 103.19 & 107.58 & 109.34 & 1.23 & 28.1 & 52 \\
\hline
\end{tabular}




\section{Table 7}

Correlation Matrix of GNMA I Mortgage-Backed Security Prices. This table presents the correlation matrix for the GNMA I mortgagebacked security TBA prices for the indicated coupon rates. Since not all time series of prices have the same length, pairwise correlations are based only on months where there is an observation for both series. Correlations which cannot be computed because of nonoverlapping observations are designated with a hyphen. The data are monthly for the period from June 1992 to June 2002.

\begin{tabular}{|c|c|c|c|c|c|c|c|c|c|}
\hline Coupon Rate & 5.50 & 6.00 & 6.50 & 7.00 & 7.50 & 8.00 & 8.50 & 9.00 & 9.50 \\
\hline 5.50 & 1.000 & .975 & .966 & .931 & .816 & .672 & .566 & .180 & - \\
\hline 6.00 & .975 & 1.000 & .998 & .994 & .979 & .949 & .911 & .791 & .716 \\
\hline 6.50 & .966 & .998 & 1.000 & .997 & .982 & .948 & .909 & .797 & .746 \\
\hline 7.00 & .931 & .994 & .997 & 1.000 & .992 & .958 & .902 & .782 & .720 \\
\hline 7.50 & .816 & .979 & .982 & .992 & 1.000 & .985 & .936 & .823 & .748 \\
\hline 8.00 & .672 & .949 & .948 & .958 & .985 & 1.000 & .972 & .877 & .799 \\
\hline 8.50 & .566 & .911 & .909 & .902 & .936 & .972 & 1.000 & .951 & .861 \\
\hline 9.00 & .180 & .791 & .797 & .782 & .823 & .877 & .951 & 1.000 & .928 \\
\hline 9.50 & - & .716 & .746 & .720 & .748 & .799 & .861 & .928 & 1.000 \\
\hline
\end{tabular}




\section{Table 8}

Summary Statistics for Original Credit Spreads. This table reports summary statistics for the original credit spreads measured in basis points for mortgage-backed securities with the indicated coupon rates. The credit spread is computed by taking the (positive) difference between the coupon rate and the par coupon rate at the implied date when the underlying mortgages were originated. This implied date is based on weighted average maturity or WAM of the mortgages.

\begin{tabular}{|c|c|c|c|c|c|c|}
\hline Coupon Rate & Average & Minimum & Median & Maximum & $\begin{array}{l}\text { Standard } \\
\text { Deviation }\end{array}$ & $\begin{array}{r}\text { Number of } \\
\text { Observations }\end{array}$ \\
\hline 5.50 & 0.0 & 0.0 & 0.0 & 0.0 & 0.0 & 29 \\
\hline 6.00 & 0.0 & 0.0 & 0.0 & 4.0 & 0.4 & 104 \\
\hline 6.50 & 2.2 & 0.0 & 0.0 & 28.0 & 6.1 & 111 \\
\hline 7.00 & 14.5 & 0.0 & 7.0 & 104.0 & 21.7 & 120 \\
\hline 7.50 & 23.9 & 0.0 & 0.0 & 154.0 & 38.0 & 121 \\
\hline 8.00 & 34.6 & 0.0 & 14.0 & 175.0 & 47.7 & 121 \\
\hline 8.50 & 67.8 & 0.0 & 49.0 & 232.0 & 55.2 & 121 \\
\hline 9.00 & 82.9 & 0.0 & 91.0 & 278.0 & 62.1 & 115 \\
\hline 9.50 & 68.3 & 0.0 & 69.0 & 130.0 & 49.0 & 52 \\
\hline
\end{tabular}


Table 9

Regressions of Changes in GNMA I Mortgage-Backed Security Prices on Changes in Term Structure and Volatility Variables. This table reports the results of regression of monthly changes in the mortgage-backed security prices for the indicated coupon rates on monthly changes in the three-month Libor, 10-year swap, and 30-year swap rates, and monthly changes in the average volatility of 2-year through 10-year interest rate caps.

$$
\Delta T B A=\beta_{0}+\beta_{1} \Delta 3 M O+\beta_{2} \Delta 10 Y R+\beta_{3} \Delta 30 Y R+\beta_{4} \Delta V O L+\epsilon
$$

\begin{tabular}{|c|c|c|c|c|c|c|c|c|c|c|c|c|}
\hline & $\beta_{0}$ & $\beta_{1}$ & $\beta_{2}$ & $\beta_{3}$ & $\beta_{4}$ & $t_{\beta_{0}}$ & $t_{\beta_{1}}$ & $t_{\beta_{2}}$ & $t_{\beta_{3}}$ & $t_{\beta_{4}}$ & $R^{2}$ & $\mathrm{~N}$ \\
\hline 5.50 & 0.115 & 0.556 & -4.256 & -1.147 & -0.039 & 0.98 & 1.20 & -4.03 & -0.92 & -0.62 & 0.899 & 27 \\
\hline 6.00 & -0.003 & -0.044 & -3.608 & -2.290 & -0.098 & -0.06 & -0.24 & -6.20 & -3.43 & -2.58 & 0.902 & 103 \\
\hline 6.50 & -0.005 & -0.135 & -3.485 & -1.860 & -0.105 & -0.10 & -0.73 & -6.28 & -2.95 & -2.87 & 0.889 & 110 \\
\hline 7.00 & -0.015 & -0.355 & -2.495 & -2.216 & -0.115 & -0.34 & -1.93 & -4.65 & -3.66 & -3.26 & 0.850 & 119 \\
\hline 7.50 & -0.011 & -0.466 & -1.735 & -2.058 & -0.111 & -0.24 & -2.43 & -3.08 & -3.24 & -3.03 & 0.773 & 120 \\
\hline 8.00 & -0.009 & -0.525 & -1.529 & -1.203 & -0.086 & -0.18 & -2.62 & -2.60 & -1.81 & -2.26 & 0.641 & 120 \\
\hline 8.50 & -0.013 & -0.571 & -0.956 & -0.773 & -0.036 & -0.29 & -3.05 & -1.74 & -1.25 & -1.01 & 0.495 & 120 \\
\hline 9.00 & -0.013 & -0.558 & -0.587 & -0.482 & -0.018 & -0.32 & -3.35 & -1.18 & -0.85 & -0.60 & 0.399 & 113 \\
\hline 9.50 & 0.080 & -0.123 & -1.369 & 0.838 & 0.018 & 1.30 & -0.28 & -1.63 & 0.98 & 0.35 & 0.237 & 50 \\
\hline
\end{tabular}




\section{Table 10}

Summary Statistics for the Fitted Recursive Model. This table reports summary statistics from fitting the optimal recursive model to historical discount mortgage-backed security prices. For each of the 121 months in the sample period, the fitting procedure searches for the implied turnover rate that best fits (in terms of the root-mean-squared error) the prices of the mortgage-backed securities with prices less than 100. Root-mean-squared errors are expressed in units of dollars per 100 principal amount. The turnover rate is the annualized probability of an exogenous payoff and is expressed as a percentage. The implied par mortgage spread is the difference between the par mortgage rate implied by the model and the 10 -year swap rate and is expressed as an annualized percentage rate. Similarly for the actual par mortgage spread.

\begin{tabular}{|c|c|c|c|c|c|c|}
\hline & Average & Minimum & Median & Maximum & $\begin{array}{l}\text { Standard } \\
\text { Deviation }\end{array}$ & $\begin{array}{l}\text { Correlation } \\
\text { With Actual }\end{array}$ \\
\hline Root Mean Squared Error & 0.22 & 0.00 & 0.16 & 0.85 & 0.21 & \\
\hline $\begin{array}{r}\text { Implied Turnover Rate } \\
\text { Actual Turnover Rate } \\
\text { Difference in Rates }\end{array}$ & $\begin{array}{r}5.59 \\
6.04 \\
-0.45\end{array}$ & $\begin{array}{r}1.35 \\
4.60 \\
-5.25\end{array}$ & $\begin{array}{r}5.15 \\
5.95 \\
-0.64\end{array}$ & $\begin{array}{r}10.00 \\
7.44 \\
3.33\end{array}$ & $\begin{array}{l}1.48 \\
0.66 \\
1.41\end{array}$ & 0.327 \\
\hline $\begin{array}{r}\text { Implied Par Mortgage Spread } \\
\text { Actual Par Mortgage Spread } \\
\text { Difference in Spreads }\end{array}$ & $\begin{array}{l}0.70 \\
0.65 \\
0.05\end{array}$ & $\begin{array}{r}0.36 \\
0.34 \\
-0.20\end{array}$ & $\begin{array}{l}0.65 \\
0.65 \\
0.01\end{array}$ & $\begin{array}{l}1.19 \\
0.92 \\
0.54\end{array}$ & $\begin{array}{l}0.19 \\
0.12 \\
0.14\end{array}$ & 0.686 \\
\hline
\end{tabular}


Table 11

Summary Statistics for Implied Credit Spreads. This table reports summary statistics for the implied credit spreads measured in basis points for mortgage-backed securities with the indicated coupon rates. The implied credit spread is determined by solving for the credit spread that sets the recursive model price equal to the market price for each premium mortgage-backed security in the sample.

\begin{tabular}{|c|c|c|c|c|c|c|}
\hline Coupon Rate & Average & Minimum & Median & Maximum & $\begin{array}{l}\text { Standard } \\
\text { Deviation }\end{array}$ & $\begin{array}{r}\text { Number of } \\
\text { Observations }\end{array}$ \\
\hline 5.50 & 0.0 & 0.0 & 0.0 & 0.0 & 0.0 & 0 \\
\hline 6.00 & 0.0 & 0.0 & 0.0 & 0.0 & 0.0 & 3 \\
\hline 6.50 & 6.5 & 0.0 & 0.0 & 122.1 & 24.9 & 24 \\
\hline 7.00 & 10.2 & 0.0 & 0.0 & 250.0 & 35.3 & 56 \\
\hline 7.50 & 21.1 & 0.0 & 17.8 & 81.6 & 18.9 & 79 \\
\hline 8.00 & 45.7 & 0.0 & 44.1 & 102.5 & 20.6 & 106 \\
\hline 8.50 & 82.6 & 22.3 & 82.8 & 149.2 & 24.8 & 116 \\
\hline 9.00 & 119.2 & 52.7 & 123.3 & 172.4 & 25.7 & 115 \\
\hline 9.50 & 168.1 & 113.2 & 170.7 & 210.0 & 24.4 & 52 \\
\hline
\end{tabular}


Table 12

Regression of Implied Credit Spreads on Borrower-Credit-Related Variables. This table reports the results of regressing the implied credit spreads for the premium mortgage-backed securities on the original credit spreads for the mortgages in the underlying pools and the percentage of the original mortgage balance that has been prepaid.

Implied Spread $=\beta_{0}+\beta_{1}$ Original Spread $+\beta_{2}$ Percent Prepaid $+\epsilon$

\begin{tabular}{|c|c|c|c|c|c|c|c|c|}
\hline $\begin{array}{r}\text { Independent } \\
\text { Variables }\end{array}$ & $\beta_{0}$ & $\beta_{1}$ & $\beta_{2}$ & $t_{\beta_{0}}$ & $t_{\beta_{1}}$ & $t_{\beta_{2}}$ & $R^{2}$ & $\mathrm{~N}$ \\
\hline Original Spread Only & 48.33 & 0.503 & - & 17.58 & 13.04 & - & 0.238 & 545 \\
\hline Percent Prepaid Only & 39.97 & - & 1.509 & 12.57 & - & 13.19 & 0.243 & 545 \\
\hline Both Variables & 28.86 & 0.389 & 1.175 & 9.37 & 10.62 & 10.79 & 0.373 & 545 \\
\hline
\end{tabular}




\section{Table 13}

Summary Statistics for the Out-of-Sample Pricing Errors from the Recursive Model. This table reports summary statistics for the pricing errors resulting from calibrating the recursive model to the implied credit spreads from the previous month and applying the model to the current month. The pricing error is the difference between the actual mortgage-backed security price and the recursive model price.

\begin{tabular}{|c|c|c|c|c|c|}
\hline Coupon & Mean Pricing Error & $\begin{array}{r}\text { Standard Deviation } \\
\text { of Pricing Error }\end{array}$ & $\begin{array}{r}t \text {-Statistic for } \\
\text { Mean Pricing Error }\end{array}$ & $\begin{array}{r}\text { Root-Mean-Squared } \\
\text { Error }\end{array}$ & $\begin{array}{r}\text { Number of } \\
\text { Observations }\end{array}$ \\
\hline 5.50 & -0.437 & 0.613 & -3.38 & 0.744 & 29 \\
\hline 6.00 & -0.438 & 1.027 & -4.35 & 1.112 & 104 \\
\hline 6.50 & -0.398 & 0.815 & -5.14 & 0.903 & 111 \\
\hline 7.00 & -0.280 & 0.713 & -4.31 & 0.763 & 120 \\
\hline 7.50 & -0.017 & 0.632 & -0.30 & 0.629 & 120 \\
\hline 8.00 & 0.127 & 0.670 & 2.08 & 0.680 & 120 \\
\hline 8.50 & 0.209 & 0.765 & 2.99 & 0.790 & 120 \\
\hline 9.00 & 0.310 & 0.887 & 3.73 & 0.937 & 114 \\
\hline 9.50 & 0.597 & 1.032 & 4.13 & 1.183 & 51 \\
\hline All & -0.036 & 0.858 & -1.25 & 0.858 & 889 \\
\hline
\end{tabular}




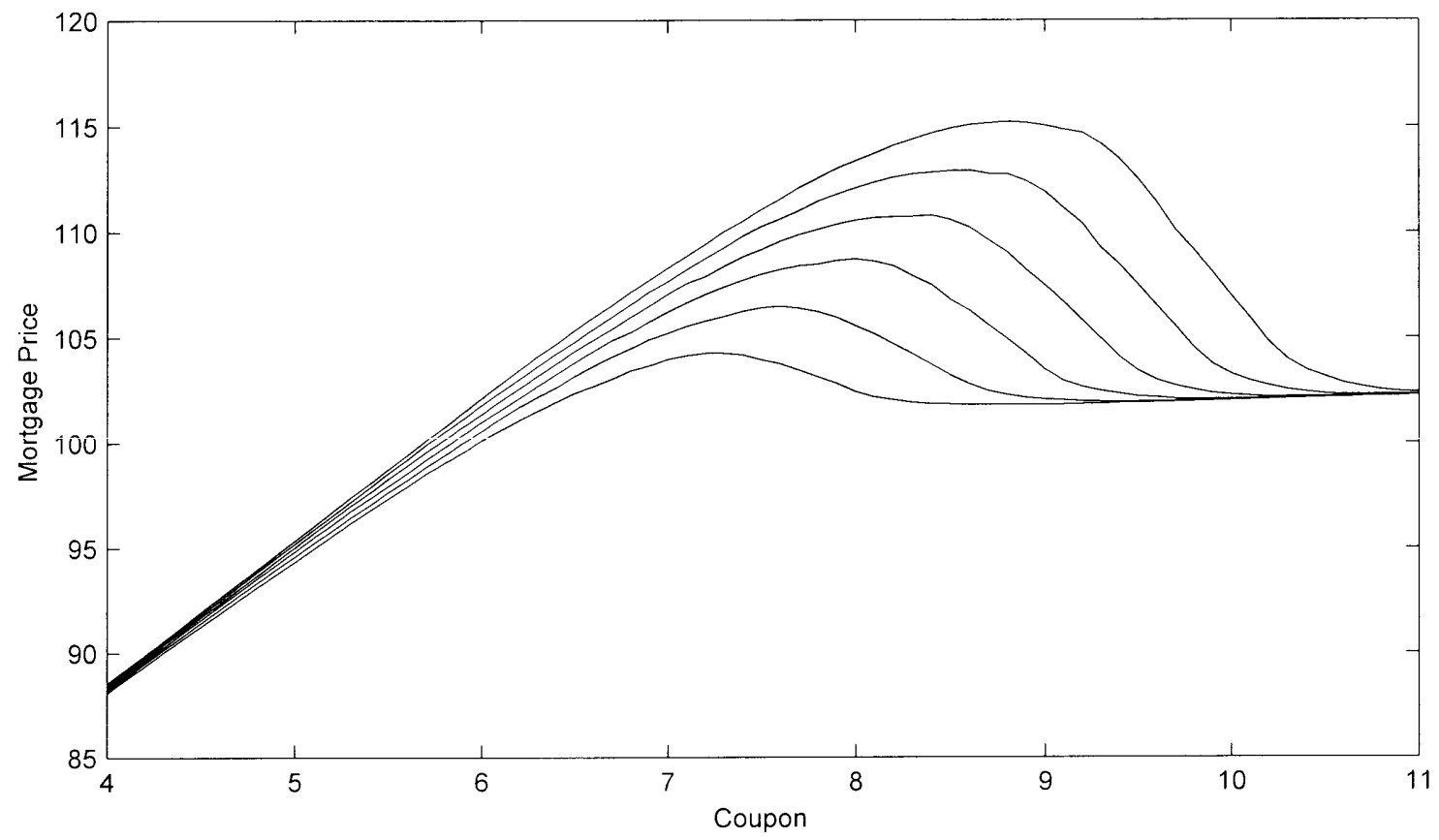

Figure 1. Mortgage-Backed Security Values as Functions of the Coupon Rate for Varying Levels of the Credit Spread. This graph plots the values of mortgage-backed securities implied by the recursive model as functions of the coupon rate and for values of the credit spread ranging from zero (giving the lowest mortgage-backed security values) to 250 basis points (giving the highest mortgage-backed security values) in increments of 50 basis points. 


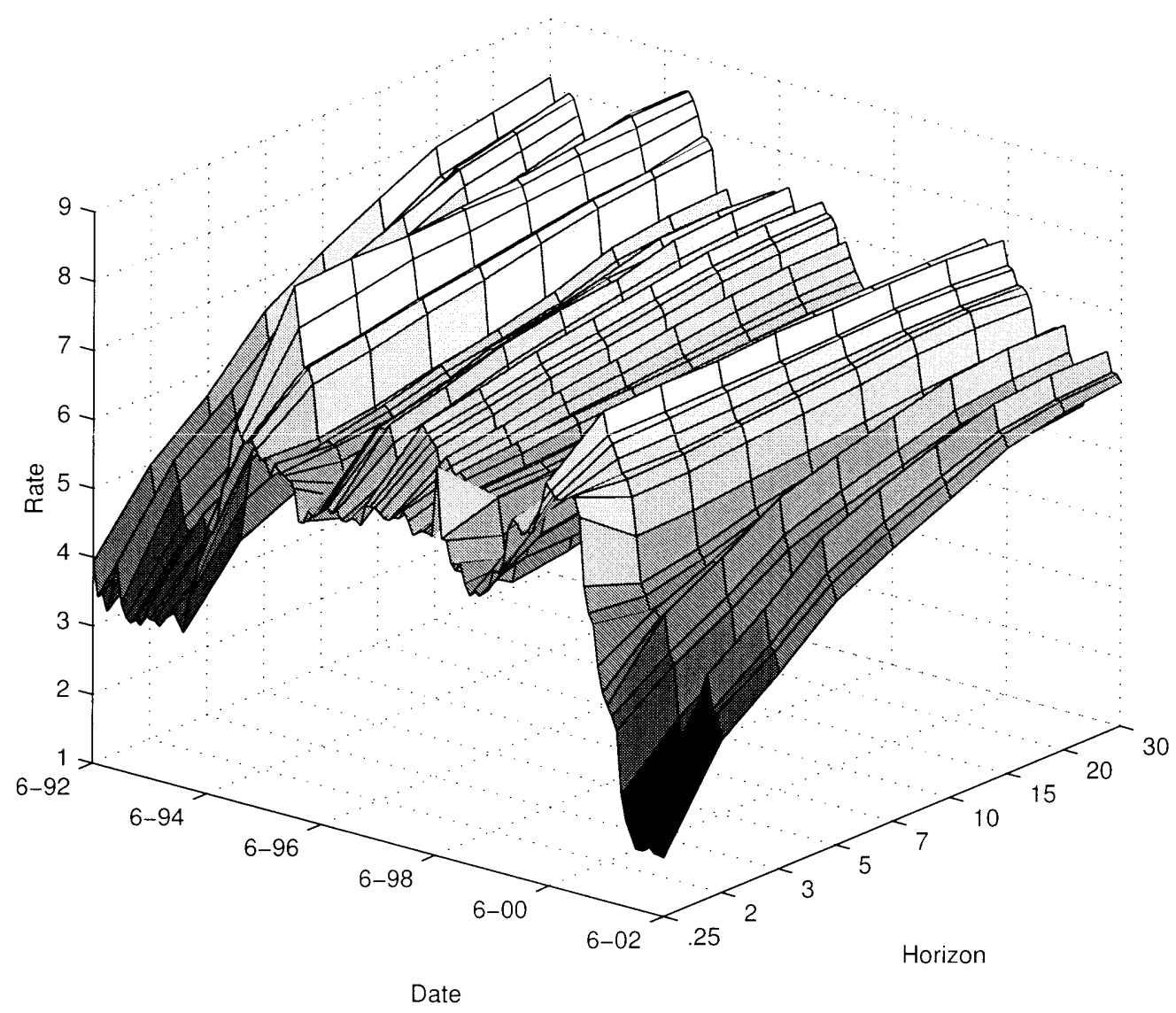

Figure 2. The Term Structure of Swap Rates. This graph plots the term structure of Libor and swap rates for the indicated maturities. The data consist of monthly observations from June 1992 to June 2002. 


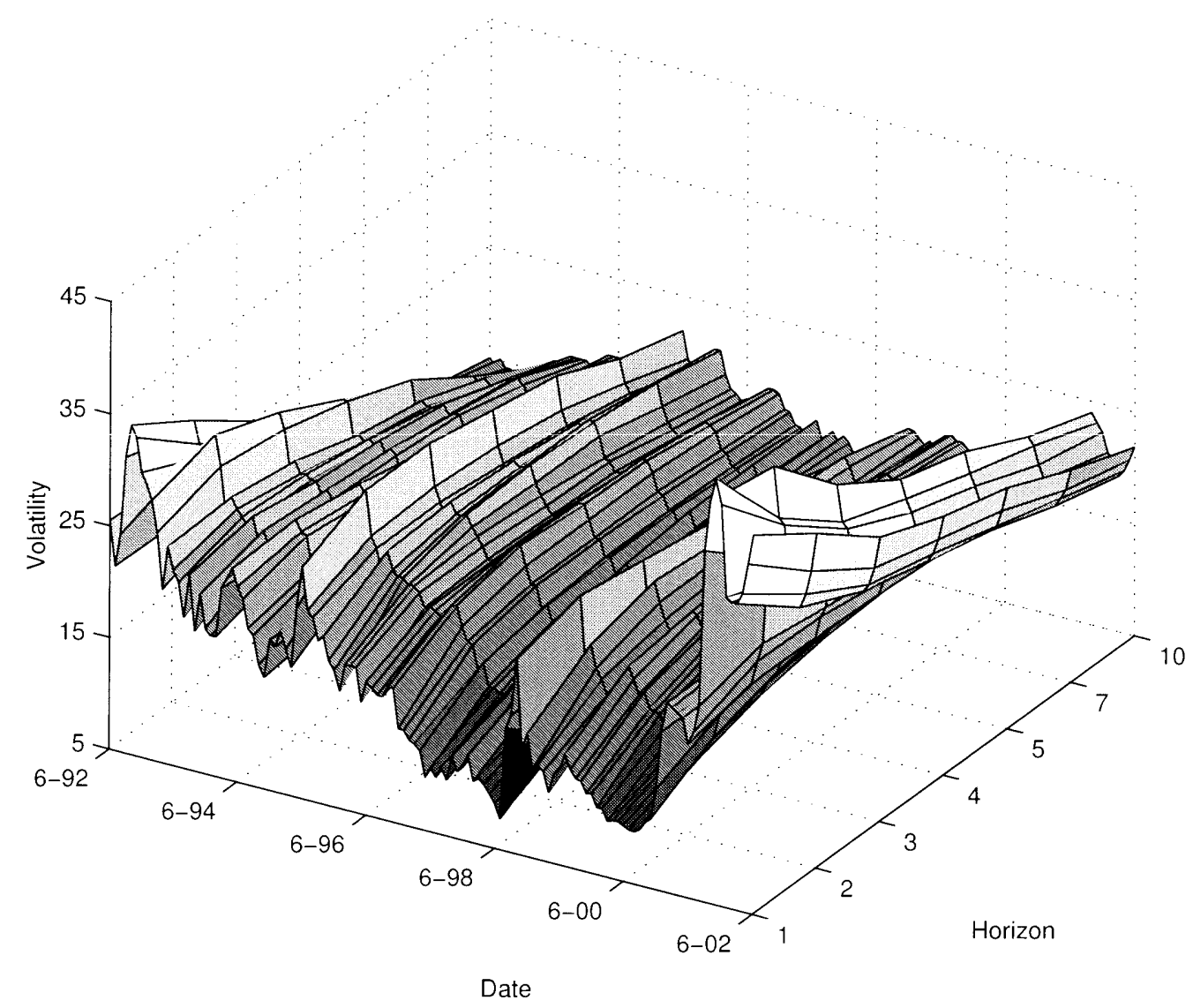

Figure 3. The Term Structure of Interest-Rate Cap Volatility. This graph plots the term structure of Black-model Libor cap volatilities for the indicated maturities. The data consist of monthly observations from June 1992 to June 2002. 


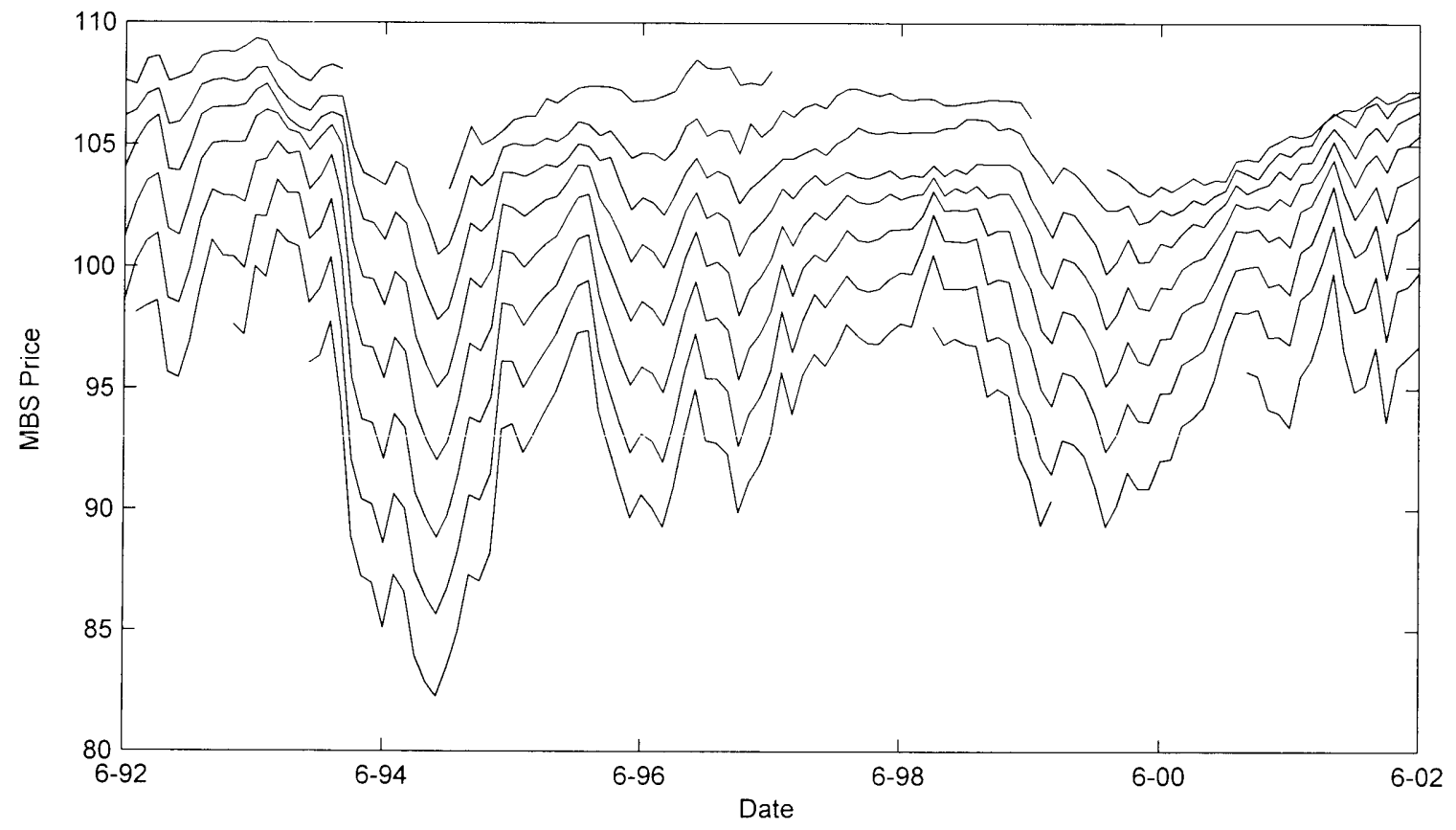

Figure 4. Historical GNMA I Mortgage-Backed Security Values. This graph plots the values of GNMA I mortgage-backed securities with coupon rates ranging from 5.50 percent (giving the lowest values) to 9.50 percent (giving the highest values) in increments of 50 basis points. The data consist of monthly observations from June 1992 to June 2002. 


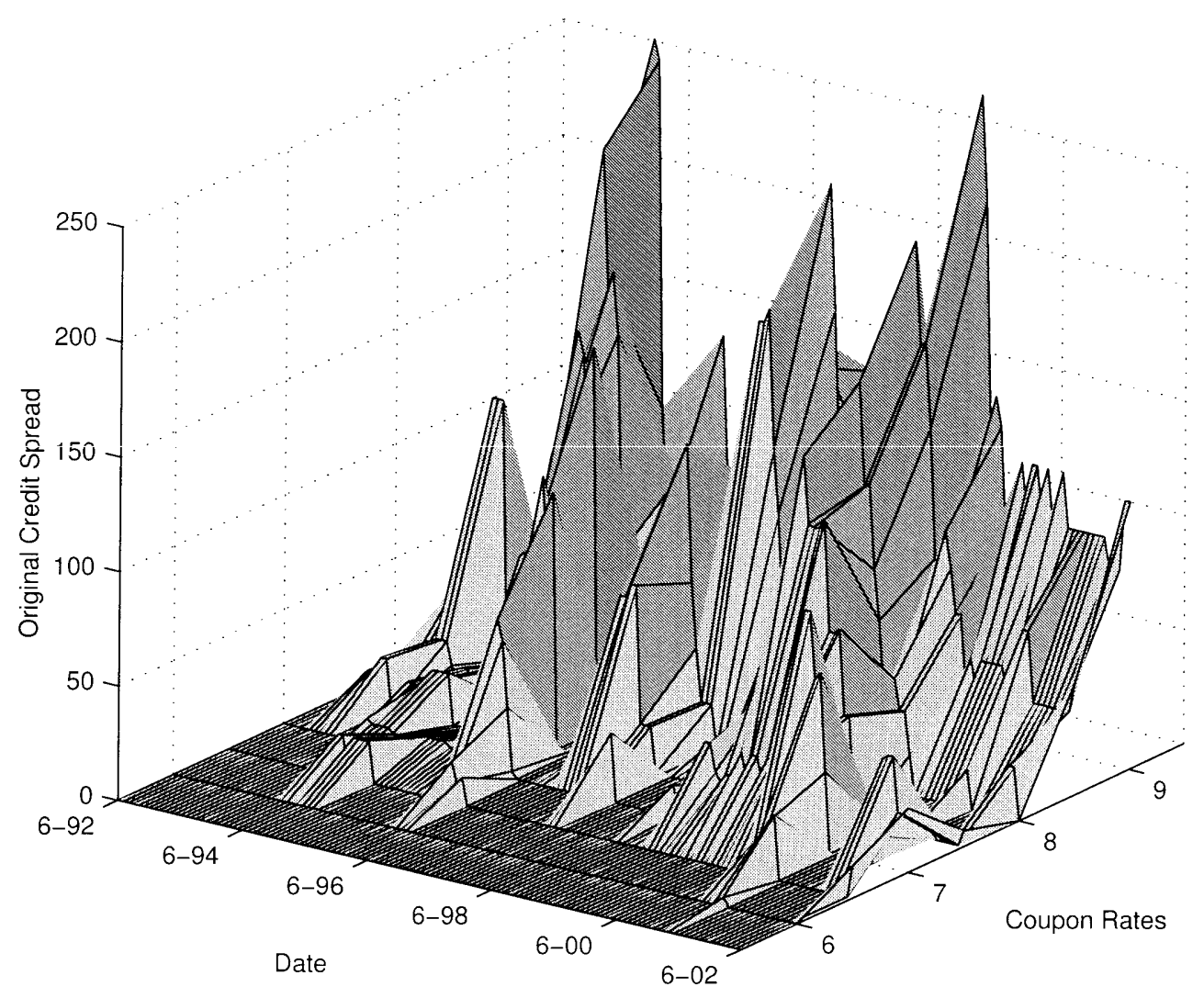

Figure 5. Original Credit Spreads for the GNMA I Mortgage-Backed Securities. This graph plots the original credit spread for the indicated coupon rates. The original credit spread is measured as the difference between the coupon rate of the mortgage-backed security and the prevailing par mortgage rate at the time the underlying mortgages were originated. The data consist of monthly observations from June 1992 to June 2002. 


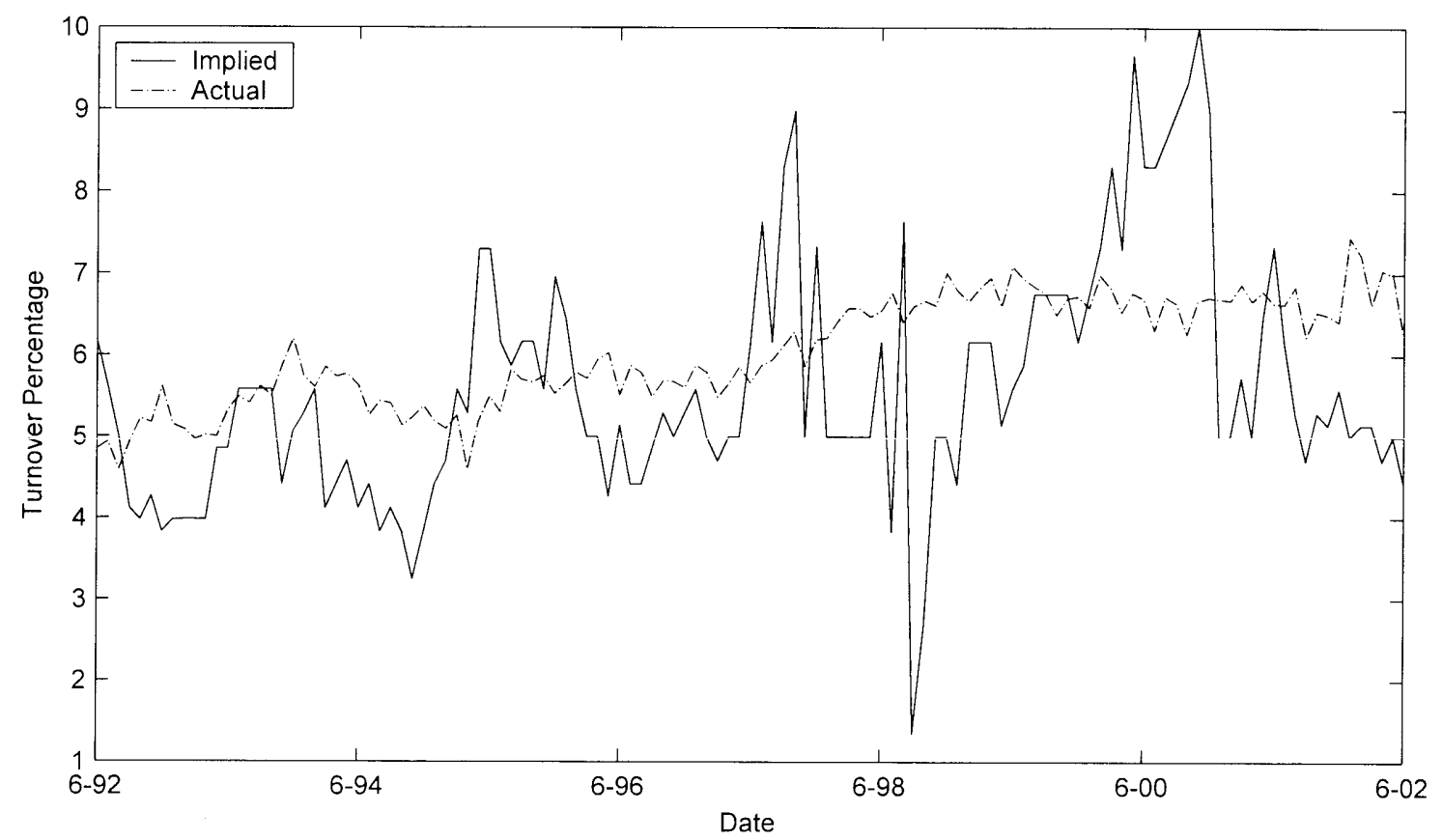

Figure 6. Implied and Actual Turnover Percentages. This graph plots the annualized percentage probability implied from the recursive model of a mortgage being paid off for exogenous reasons. Also shown is the actual seasonally-adjusted percentage turnover of single-family homes in the U.S. 


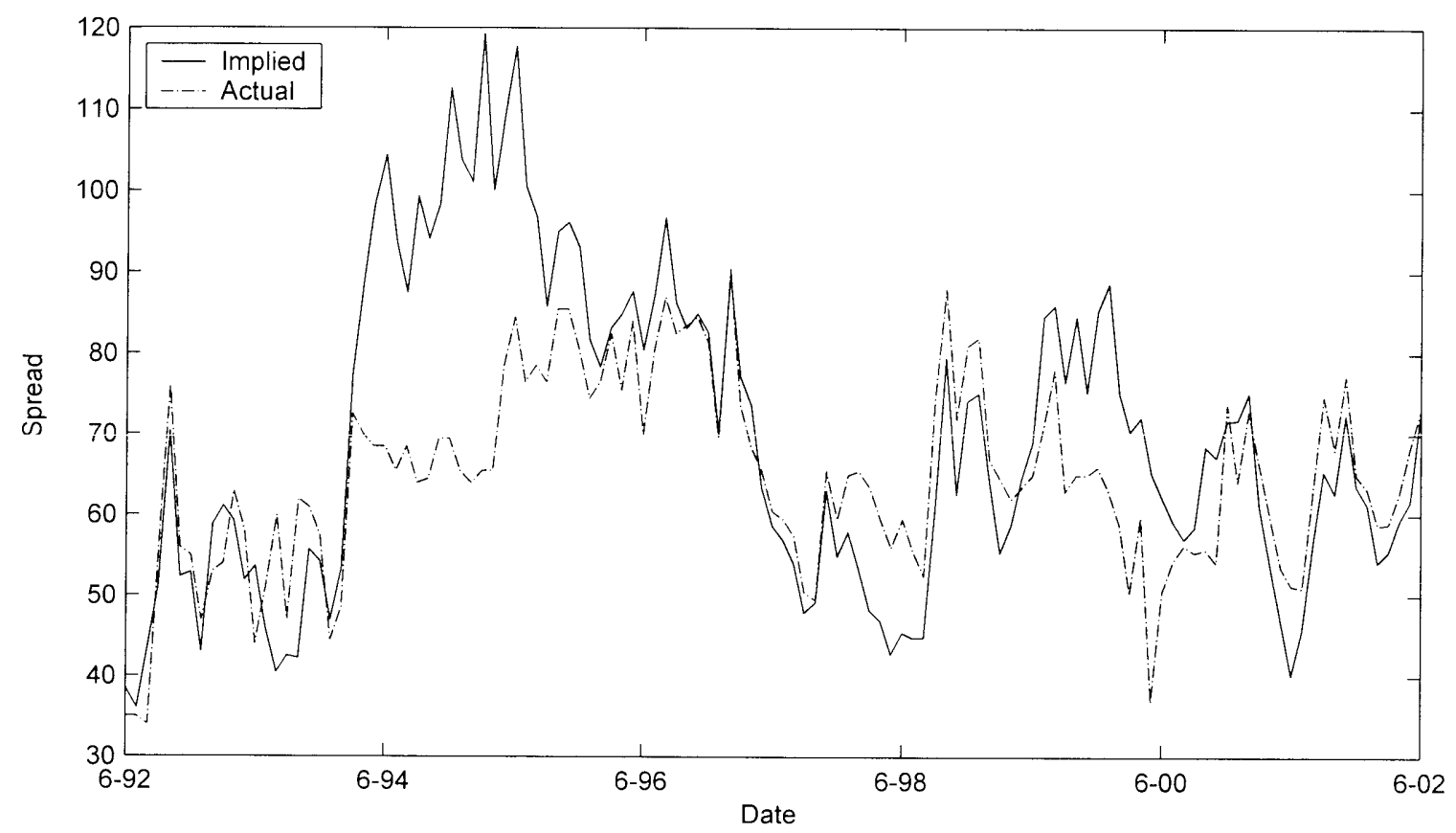

Figure 7. Implied and Actual Spread of the Par Mortgage Rate over the TenYear Swap Rate. This graph plots the difference between the par mortgage rate implied by the recursive model and the ten-year swap rate. Also plotted is the difference between the actual GNMA I par mortgage rate and the ten-year swap rate. 


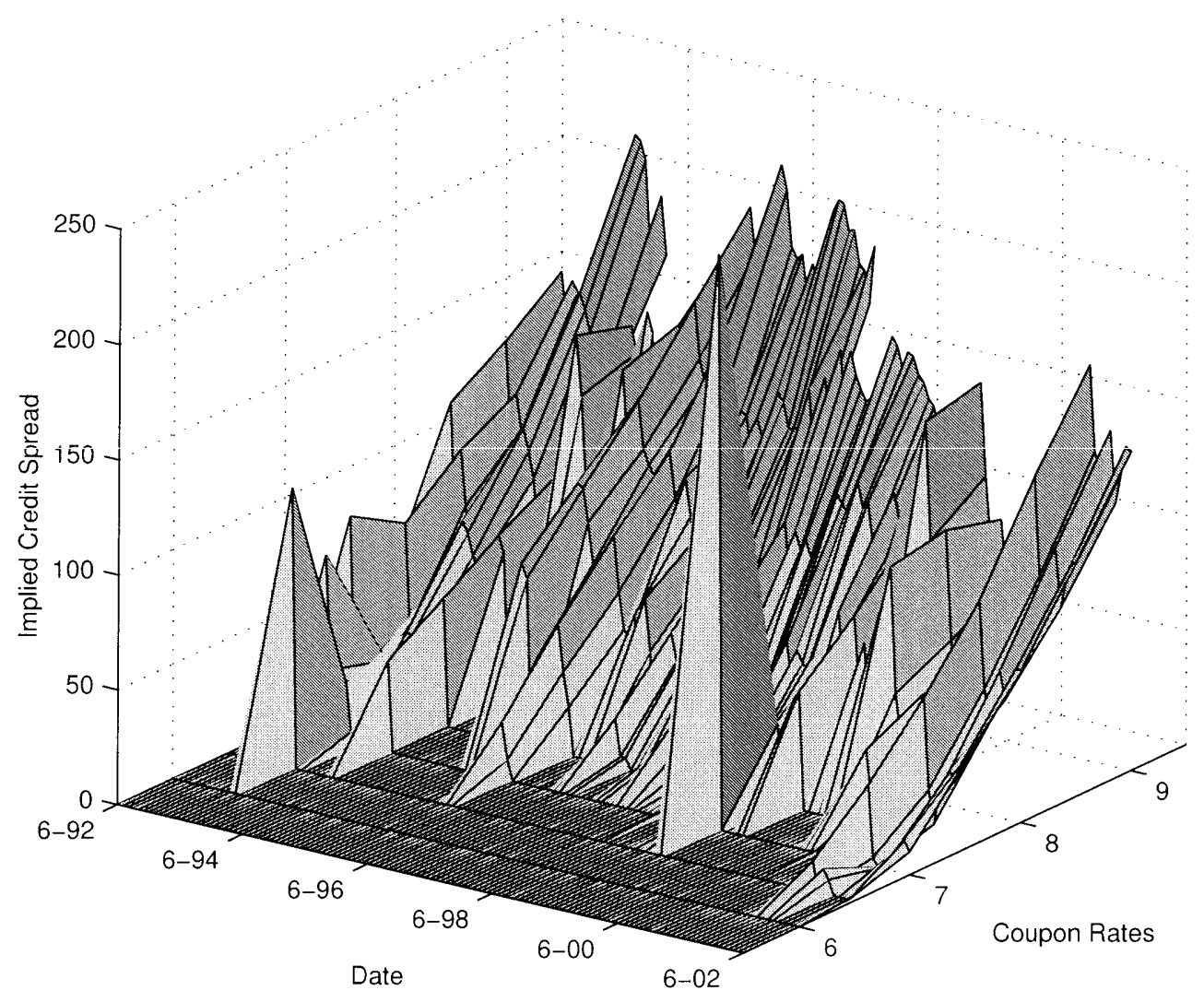

Figure 8. Implied Credit Spreads from the Recursive Model for the Mortgage-Backed Securities. This graph plots the credit spreads implied from the recursive model for the mortgage-backed securities with the indicated coupon rates. 

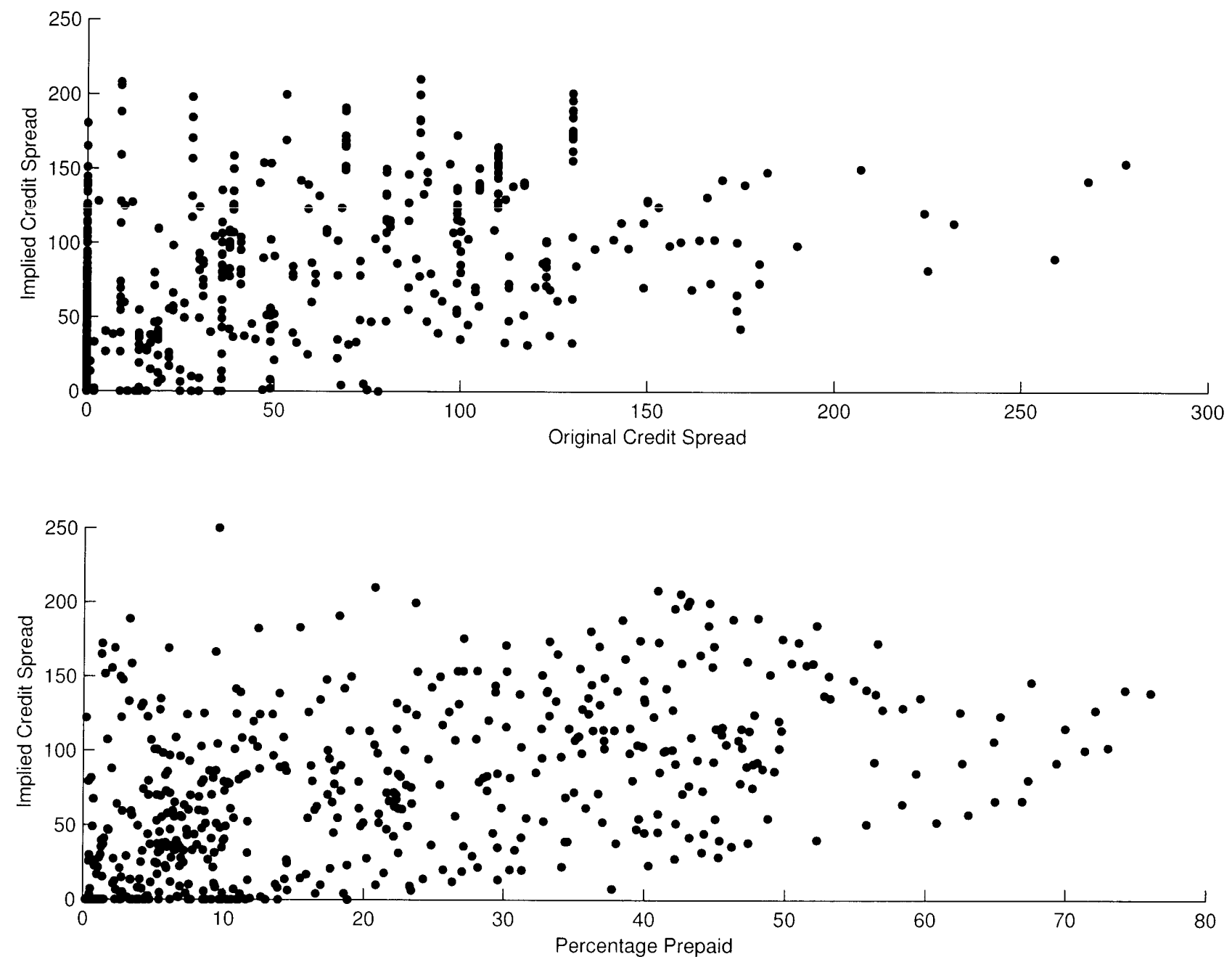

Figure 9. Scatterdiagrams of the Implied Credit Spread. The top panel plots the implied credit spread as a function of the original credit spread. The bottom panel plots the implied credit spread as a function of the percentage of the original principal amount of the mortgages in the pools underlying the mortgage-backed security that has been paid off. 